\title{
The Scope of Pharmacological and Clinical Effects of Modern Antihistamines, With a Special Focus on Rupatadine
}

\section{Proceedings from a Satellite Symposium held at the 21st World Allergy Congress, Buenos Aires, December 8, 2009}

\author{
Authors \\ Martin K. Church, ${ }^{1}$ Jorge F. Máspero, ${ }^{2}$ Marcus Maurer, ${ }^{3}$ Dermot Ryan ${ }^{4}$ \\ Editors \\ G. Walter Canonica, ${ }^{5}$ Carlos E. Baena-Cagnani ${ }^{6}$
}

\begin{abstract}
PREFACE
A llergic diseases are a global health problem that remain under-diagnosed and often are not adequately treated. Allergic rhinitis and urticaria, in particular, are examples of bothersome conditions that can markedly impair the quality of life of affected individuals through negative effects on sleep, social activities (including sport and leisure), ability to work, and school performance. These diseases cannot be cured at the present time, but current first-line treatments such as the highly effective nonsedating second-generation antihistamines can markedly reduce symptoms while at the same time improving the patient's well-being. They achieve these benefits through simultaneous inhibition of two or more chemical mediators involved in the immune-allergic cascade and this suggests that they have advantages (rapid and prolonged action, once-daily administration, greater convenience, and better tolerability/safety and efficacy) over firstgeneration antihistamines.

In this satellite symposium the prestigious panel of experts will provide their perspectives relating to advances that are being made in our understanding of allergic/inflammatory disorders such as rhinitis and urticaria, and also some recent clinical findings regarding the effectiveness of the

From the ${ }^{1}$ Inmunopharmacology School of Medicine of the University Southamptom, UK; ${ }^{2}$ Head Pediatric Allergy, Deutsche Hospital, Buenos Aires, Argentina; ${ }^{3}$ Dermatology and Allergy, Hospital Charite, Berlin, Germany; ${ }^{4}$ Clinical Research Fellow, University of Aberdeen, United Kingdon; ${ }^{5}$ Allergy \& Respiratory Diseases Clinic, Genoa University, Italy; and ${ }^{6}$ Faculty Medicine Catholic University Cordoba, Argentina.

This satellite symposium was kindly sponsored by Grupo Uriach. The authors and editors would like to thank Steve Clissold and Pablo Pons from Content Ed Net Madrid for editorial assistance.

Correspondence to: G. Walter Canonica, MD, Professor, Allergy and Respiratory Diseases, DIMI, Department of Internal Medicine, University of Geona, Largo Rosanna Benzilo, Genoa 1-16132, Italy.

E-mail: canonica@unige.it.

Copyright $(\subset) 2010$ by World Allergy Organization
\end{abstract}

second-generation antihistamines in debilitating disorders such as allergic rhinitis and chronic urticaria.

\section{SECTIONS}

Section 1: Multiple Pharmacological Activities of Novel Antihistamines, Martin K. Church (United Kingdom) p. S1-S4.

Section 2: Persistent Allergic Rhinitis: Long-Term Treatment with Antihistamines, Jorge F. Máspero (Argentina) p. S4-S9. Section 3: Effective New Antihistamines in Dermatology: Urticaria and Other Conditions, Marcus Maurer (Germany) p. S9-S12.

Section 4: Management of Allergies in the Primary Care Environment, Dermot Ryan (United Kingdom) p. S13-S16.

\section{SECTION 1. MULTIPLE PHARMACOLOGICAL ACTIVITIES OF NOVEL ANTIHISTAMINES}

\section{Abstract}

Allergic inflammation is a complex and multifactorial IgE-mediated immuno-inflammatory cascade that is associated with the epithelial accumulation of effector cells such as mast cells, eosinophils and basophils, and the formation and release of a variety of different inflammatory mediators. The chemical mediators that act in concert to produce these effects can be divided into 3 groups: preformed granule associated mediators (eg, histamine and proteases), phospholipid-derived mediators [eg, eicosanoids and platelet-activating factor (PAF)], and chemokines and cytokines. The role of histamine in allergic inflammation is unequivocal; however, other mediators are clearly involved in the inflammatory process and their roles are beginning to become better defined. For example, PAF increases vascular permeability and is becoming increasingly recognized as an important mediator. The clinical importance of PAF has been highlighted by the finding that allergic responses, including anaphylaxis, seem to be more severe in patients deficient in PAF-acetyl- 
hydrolase, the enzyme that inactivates PAF. There is an emerging view that drugs that can inhibit a broader range of inflammatory agents may prove to be more effective in providing symptomatic relief in allergic disorders than those targeted at a single mediator. In this regard, rupatadine is a novel antihistamine that is also an inhibitor of PAF. Some recent pharmacological and clinical findings with this agent are presented in this overview.

\section{INTRODUCTION}

A lergic inflammation is a complex immune-inflammatory cascade that primarily developed as a protection against parasite infestation. The chemical mediators which act in concert to facilitate these effects can be divided into 3 types: preformed granule-associated mediators (eg, mast cell-derived histamine and proteases); newly generated phospholipid-derived mediators [eg, eicosanoids and platelet-activating factor (PAF)], and macromolecular chemokines and cytokines (Fig. 1-1). The role of histamine as a prominent mediator in the pathophysiology of allergic rhinitis and urticaria is unequivocal. Antihistamines have traditionally been considered to exert their effects through antagonism of $\mathrm{H}_{1}$-receptors. However, today, we have a better understanding of the mechanism of action of this class of drugs and they seem to act on the $\mathrm{H}_{1}$-receptor in a positive (agonist) way and they are now classed as inverse agonists. ${ }^{1-3}$ Histamine is clearly not the only mediator involved in the inflammatory process and there is an emerging view that drugs which can inhibit a broader range of inflammatory agents may prove to be more effective in providing symptomatic relief in both allergic rhinitis and chronic urticaria. ${ }^{4}$

\section{ALLERGIC RHINITIS AND URTICARIA}

Allergic rhinitis and urticaria are diseases or, more appropriately, groups of diseases that between them represent one of the most common reasons for a patient to visit their general practitioner. They are clearly very different diseases, but given the fact that they are both responsive to treatment with antihistamines, do they have elements in common?

As its name indicates allergic rhinitis is an immunologic disease resulting from allergen provocation (pollen, molds,

\section{Mast Cell Mediator Release}

\begin{tabular}{|c|c|}
\hline $\begin{array}{l}\text { Neuro- } \\
\text { peptide } \\
\text { lg }\end{array}$ & $\begin{array}{l}\text { Primary Mediators } \\
\text { (Granule-Derived) } \\
\text { - Histamine } \\
\text { - Neutral Proteases } \\
\end{array}$ \\
\hline :06 & $\begin{array}{l}\text { Secondary Mediators } \\
\text { (Phospholipid-Derived) } \\
\text { Arachidonate-derived } \\
\text { - Prostaglandins } \\
\text { - Leukotrienes } \\
\text { Phospholipid Mediator } \\
\text { - Platelet Activating } \\
\text { - Factor (PAF) }\end{array}$ \\
\hline $\begin{array}{l}\text { (Newly Transcribed) } \\
\text { - Cytokines } \\
\text { - Adhesion Molecules }\end{array}$ & \\
\hline
\end{tabular}

FIGURE 1-1. Mediator release associated with mast cell degranulation after allergen exposure. mites, etc) within the nasal passages and after initial sensitization, there is a well-defined cascade of events that follows:

- IgE-mediated stimulation of resident effector cells, such as mast cells

- Early phase inflammatory response that is mainly mast cell-mediated (sneezing, itching, and rhinorrhoea)

- Immune system activation (T- and B-lymphocytes)

- Influx and activation of secondary effector cells such as neutrophils, basophils, eosinophils, etc.

- Development of allergic inflammation, involving activated effector cells, particular the eosinophils, leading to nasal congestion/blockage.

Given the diversity of the allergic cascade and the immune response that it elicits, it is not surprising that it can vary between individuals. Indeed, genetic polymorphisms exist that can influence the IgE-mediated response and the "make-up" of cytokines that are produced after provocation. ${ }^{5}$ Our group undertook a study that investigated the dermal cytokine response to allergen in 11 patients and we observed 11 different cytokine responses. ${ }^{6}$ This suggests that genetic factors are important and that an individual's response to an allergen can be influenced at a number of levels: different mast cell response, different immune cell activation, different effector cell responses, and different sensitivity to the released inflammatory mediators.

Allergen provocation and its subsequent IgE-mediated immune response have a far less important role in the pathogenesis of urticaria. Other factors such as Complement fractions, IgG complexes associated with autoimmune diseases, neuropeptides, and many others may be involved. Stress can also be important and clearly exacerbates urticarial disease. ${ }^{7}$ As with allergic rhinitis, histamine is a key mediator in the symptomatology of urticaria and this comes from 2 pieces of evidence:

- $\mathrm{H}_{1}$-receptors are present on the blood vessels in the skin, and they are responsible for local vasodilatation and, ultimately, local edema (wheal)

- $\mathrm{H}_{1}$-receptors are present on the sensory nerves in the skin, and these are responsible for the local flare response and subsequent itching (pruritus)

However, as with allergic rhinitis, the individual responses to histamine release and the reaction to it are variable. Furthermore, a wide range of eliciting stimuli have been implicated in the pathogenesis of urticaria including physical factors, drugs, foodstuffs, infectious agents, autoimmunity, cold, etc. This diversity, combined with the individual response to provocation and stress, makes urticaria a family of diseases in which every patient can be considered different.

\section{PLATELET ACTIVATING FACTOR (PAF)}

PAF was discovered and named in the early 1970s by Benveniste and colleagues who were investigating leukocytedependent mechanisms of histamine release from rabbit platelets. ${ }^{8}$ They found that basophils sensitized with IgE degranulated in the presence of allergen, releasing histamine and a factor (PAF) that caused aggregation of platelets and 
release of histamine. They also proposed a role for PAF as a highly potent mediator in the immediate hypersensitivity-type allergic reaction and anaphylaxis.

As noted earlier, there are 3 main groups of mediators associated with mast cell degranulation. PAF is one of the group of secondary mediators and is a by-product of arachidonic acid synthesis, which is also responsible for the production of prostaglandins and leukotrienes. PAF can be produced by different pathways; there is the classic method involving mast cells, but an alternative route involving macrophage activation has been identified in mice. ${ }^{9}$

The receptor for PAF is a G-protein coupled receptor which is significantly up-regulated in allergic diseases. For example, in the nose it is present in a wide range of different cell types, but particularly in inflammatory cells (Fig. 1-2). ${ }^{10}$ With respect to allergic rhinitis, PAF increases vascular permeability and this contributes to the increased mucous secretion and rhinorrhoea associated with the disease. PAF also attracts and activates granulocytes within the nasal endothelium and this exacerbates the inflammatory response in nasal tissues. In this regard, our group found that in tissue samples granulocyte accumulation occurred very rapidly (within 8 minutes of Pselectin translocation) and this reaction is more consistent with PAF-release than with the usual cytokine response (that is slow and takes 12 hours to peak). ${ }^{11,12}$

PAF-acetylhydrolase, the enzyme that metabolizes PAF to inactive lyso-PAF (Fig. 1-3) has a number of polymorphisms and this has been shown to have a number of clinical implications. For example, Li and colleagues recently reported that in patients homozygous for the Arg 92 allele, PAF-acetylhydrolase activity was higher than in patients with the HIS 92 allele. ${ }^{13}$ Furthermore, PAF-acetylhydrolase activity was higher among survivors at 7 days compared with nonsurvivors at 7 days (Fig. 1-3). The authors noted that these data demonstrate an association between PAF-acetylhydrolase allelic variation, plasma PAF activity and clinical outcome in acute respiratory distress syndrome. ${ }^{13}$

A similar relationship has been reported for PAF, PAFacetylhydrolase and severe anaphylaxis. ${ }^{14}$ PAF-acetylhydrolase levels were measured in 9 patients with peanut allergy who had fatal anaphylaxis and these were compared with values from a range of control subjects (adults, children, allergic, nonallergic, and survivors of anaphylaxis). The proportion of patients with elevated PAF levels increased from $4 \%$ in the control group to $20 \%$ in a group with grade 1 anaphylaxis, $71 \%$ in a group with
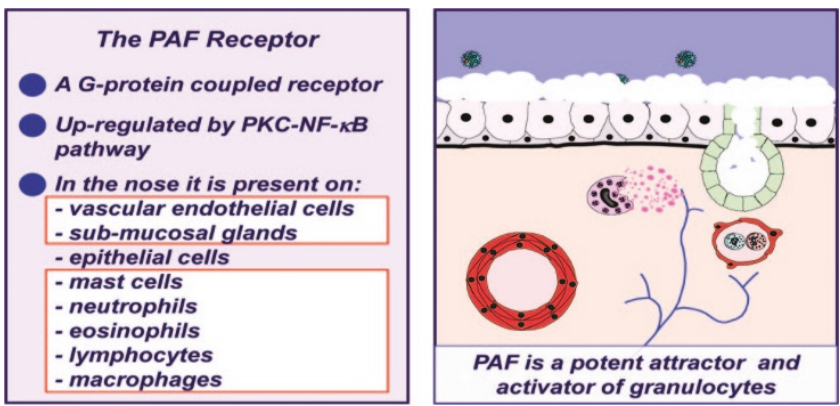

FIGURE 1-2. Platelet activating factor (PAF) and nasal inflammation.
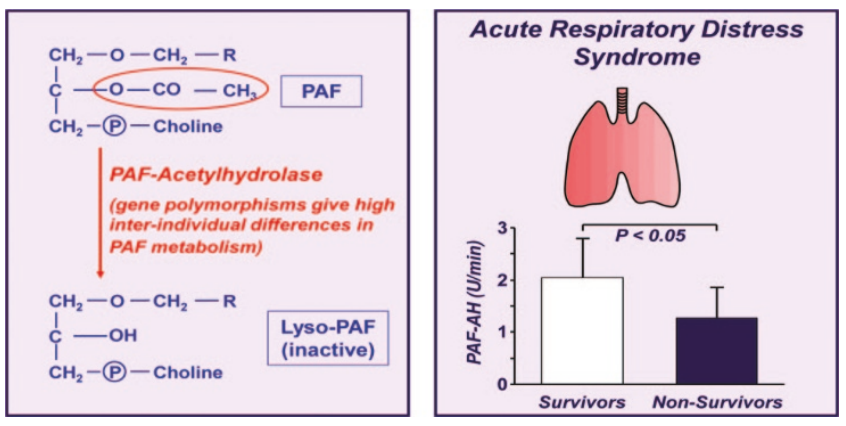

FIGURE 1-3. Platelet Activating Factor (PAF) metabolism and acute respiratory distress syndrome. ${ }^{13}$

grade 2 anaphylaxis, and 100\% in those with grade 3 anaphylaxis $(P<0.001)$. The authors noted that serum PAF-acetylhydrolase activity was significantly lower in patients with fatal peanut anaphylaxis compared with controls $(P<0.001$ for all comparisons) and concluded that increased PAF activity may contribute to the severity of anaphylaxis. ${ }^{14}$

\section{RUPATADINE}

Rupatadine is a potent second-generation antihistamine that has been shown to possess a number of antiinflammatory properties (Fig. 1-4). ${ }^{15}$ Of interest in relation to this presentation, rupatadine is a powerful antihistamine that, in addition, has been shown to be a potent inhibitor of PAF-receptors.

Pharmacokinetic studies have shown that it is rapidly absorbed with a $t_{\max }$ of $45-60$ minutes,${ }^{16}$ and this has been confirmed in clinical studies. ${ }^{15}$

A plot of rupatadine plasma concentration versus flare inhibition highlights a hysteresis loop-like response, with the highest plasma concentration observed after 5 hours, but sustained inhibition of the flare reaction being prolonged and still clinically significant after 72 hours (Fig. 1-5). This indicates that rupatadine penetrates and resides within the tissues, and explains its long duration of action, facilitating once-daily administration.

Clinical trials in patients with seasonal allergic rhinitis, perennial rhinitis, persistent rhinitis, and chronic urticaria have shown that rupatadine is at least as effective as drugs such as

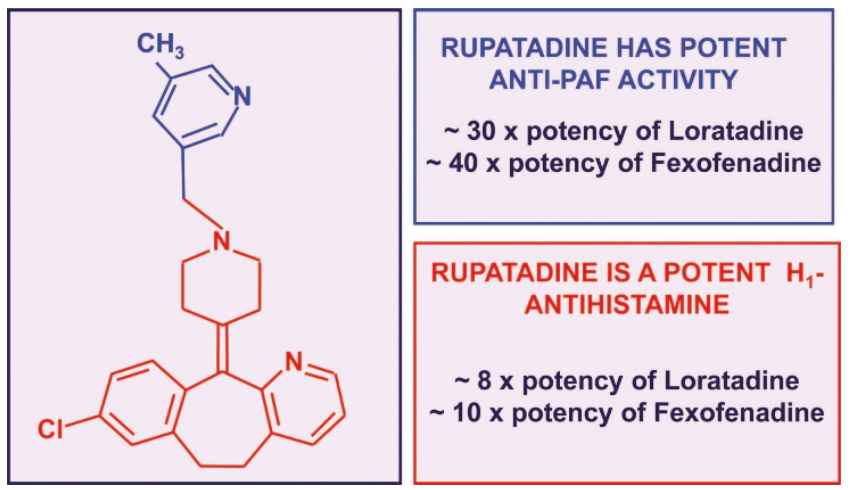

FIGURE 1-4. Structural formula and some key properties of rupatadine. ${ }^{15,16}$ 


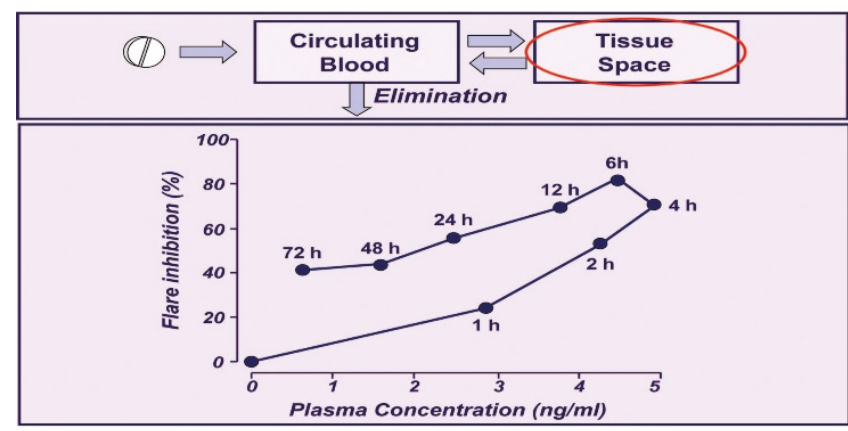

Single dose of $20 \mathrm{mg}$ Rupatadine to 18 volunteers.

FIGURE 1-5. Hysteresis of plasma rupatadine concentration and inhibition of histamine mediated flare response.

loratadine, cetirizine, desloratadine, and ebastine. In these trials it was very well tolerated and, importantly, it demonstrated no untoward cardiovascular, cognitive, or psychomotor effects. ${ }^{15}$

\section{CONCLUSIONS}

- Allergic inflammation is a complex immune-inflammatory cascade involving a wide array of mediators and effector cells

- The role of histamine in the allergic/inflammatory response is unequivocal, but other mediators such as PAF are also involved

- PAF is a potent mediator of vascular permeability thereby exacerbating rhinorrhoea

- PAF is a potent attractor and activator of granulocytes and monocytes thereby exacerbating allergic inflammation

- PAF increases the synthesis of histamine thereby exacerbating all histamine mediated effects

- PAF increases 'sensitizes' tissues to, for example, histamine and bradykinin thereby exacerbating allergic symptoms

- Failure to metabolize PAF exacerbates acute respiratory distress syndrome and anaphylaxis

- There is an emerging view that drugs that can inhibit a broader range of allergic/inflammatory mediators may prove to be more effective in both allergic rhinitis and chronic urticaria

- Rupatadine is a powerful antihistamine that, in addition, has been shown to be a potent inhibitor of PAF-receptors

\section{REFERENCES, SECTION 1}

1. Tillement J-P. Pharmacological profile of the new antihistamines. Clin Exp All Rev. 2005;5:7-11.

2. Walsh GM. Anti-inflammatory properties of antihistamines: an update. Clin Exp All Rev. 2005;5:21-25.

3. Devillier P. Comparing the new antihistamines: the role of pharmacological parameters. Clin Exp Allergy. 2006;36:5-7.

4. Howarth PH, Salagean M, Dokic D. Allergic rhinitis: not purely a histamine-related disease. Allergy. 2000;55(Suppl 64):7-16.

5. Holgate ST. The genetic basis of allergic disease. In: Holgate ST, Church MK, Lichtenstein, LM, eds. Allergy. 3rd ed. London: Mosby; 2006:205-221.

6. Clough GF, Jackson CL, Lee JJ, Jamal SC, Church MK. What can microdialysis tell us about the temporal and spatial generation of cytokines in allergen-induced responses in human skin in vivo? J Invest Dermatol. 2007;127:2799-2806.
7. Yang HY, Sun CC, Wu YC, Wang JD. Stress, insomnia, and chronic idiopathic urticaria-a case-control study. J Formos Med Assoc. 2005; 104:254-263.

8. Benveniste J, Henson PM, Cochrane CG. Leukocyte-dependent histamine release from rabbit platelets. The role of $\operatorname{IgE}$, basophils, and a platelet-activating factor. J Exp Med. 1972;136:1356-1377.

9. Finkelman FD. Anaphylaxis: lessons from mouse models. J Allergy Clin Immunol. 2007;120:506-515.

10. Shirasaki H, Seki N, Kikuchi M, Kanaizumi E, Watanabe K, Konno $\mathrm{N}$, Himi T. Expression and localization of platelet-activating factor receptor in human nasal mucosa. Ann Allergy Asthma Immunol. 2005;95:190-196.

11. Church MK, Hutson PA, Holgate ST. Effect of nedocromil sodium on early and late phase responses to allergen challenge in the guinea-pig. Drugs. 1989;37(Suppl 1):101-108.

12. Rollin S, Lemieux C, Maliba R, Favier J, Villeneuve LR, et al. VEGFmediated endothelial P-selectin translocation: role of VEGF receptors and endogenous PAF synthesis. Blood. 2004;103:3789-3797.

13. Li S, Stuart L, Zhang Y, Meduri GU, Umberger R, Yates CR. Inter-individual variability of plasma PAF-acetylhydrolase activity in ARDS patients and PAFAH genotype. J Clin Pharm Ther. 2009;34: $447-455$.

14. Vadas P, Gold M, Perelman B, Liss GM, Lack G, et al. Plateletactivating factor, PAF acetylhydrolase, and severe anaphylaxis. $N$ Engl $J$ Med. 2008;358:28-35.

15. Mullol J, Bousquet J, Bachert C, Canonica WG, Gimenez-Arnau A, et al. Rupatadine in allergic rhinitis and chronic urticaria. Allergy. 2008; 63(Suppl 87):5-28.

16. Izquierdo I, Merlos M, Garcia-Rafanell J. Rupatadine: a new selective histamine $\mathrm{H} 1$ receptor and platelet-activating factor (PAF) antagonist. A review of pharmacological profile and clinical management of allergic rhinitis. Drugs Today. 2003;39:451-468.

\section{SECTION 2. PERSISTENT ALLERGIC RHINITIS: LONG-TERM TREATMENT WITH ANTIHISTAMINES}

\section{Abstract}

The Allergic Rhinitis and its Impact on Asthma (ARIA) workshop group, in collaboration with the World Health Organization, introduced a new classification system for allergic rhinitis based on the duration of symptoms and their severity. Persistent allergic rhinitis (PER) is defined as rhinitis in which the symptoms occur more than 4 days per week and for more than 4 weeks. The disease is further classified into mild or moderate-severe depending on the level of impairment (sleep disturbances, impairment of activities, etc). Interestingly, the prevalence of PER demonstrates a wide geographic distribution and it is the most common form of rhinitis in Latin America, accounting for about $70 \%$ of cases. Rupatadine is a novel nonsedating second-generation antihistamine, which is also a PAF antagonist, which we evaluated in the treatment of PER in $>500$ Latin American patients. In this randomized, doubleblind, placebo-controlled trial rupatadine $10 \mathrm{mg}$ once-daily was compared with cetirizine $10 \mathrm{mg}$ once daily over a 12-week period. Both rupatadine and cetirizine significantly improved 6-symptom Total Symptom Scores at 4 and 8 weeks, but only rupatadine produced a statistically significant improvement at 12 weeks $(P=0.008)$. Importantly, both rupatadine and cetirizine significantly improved overall scores for quality of life, but only rupatadine significantly improved ocular symptoms $(P<0.01)$. In this trial, and in a 12-month safety study, rupatadine was found to be well-tolerated, produced no evidence of cardiotoxic effects and was associated with a high rate of 
ARIA Classifications

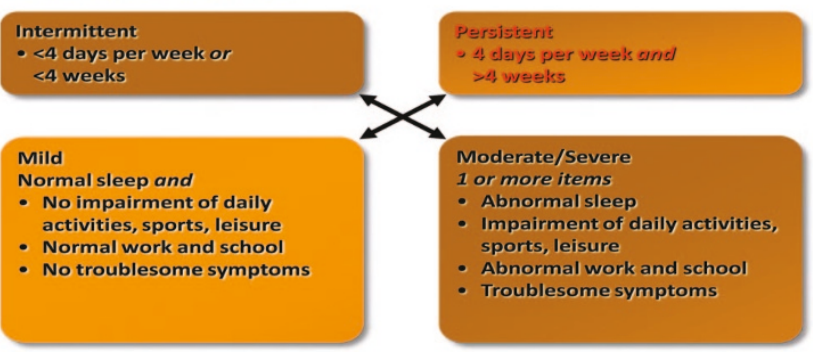

FIGURE 2-1. ARIA classification for allergic rhinitis. ${ }^{1,2}$

treatment compliance. These data indicate that once daily rupatadine is a good treatment option for patients with PER and it well-received by patients, as evidenced by high rates of long-term compliance.

\section{INTRODUCTION}

$\mathrm{T}$ he Allergic Rhinitis and its Impact on Asthma (ARIA) workshop group, in collaboration with the World Health Organization, have introduced a new classification system for allergic rhinitis based on the duration of symptoms and their severity. ${ }^{1,2}$ Persistent allergic rhinitis (PER) is defined as a symptomatology that occurs on more than 4 days per week, and for more than 4 weeks (Fig. 2-1). This is further classified into mild or moderate-severe disease depending on sleep disturbances, impairment of daily activities (including sport and leisure), abnormal work or school, or how troublesome the symptoms are.

With regards to allergic sensitization, while pollens are the most frequent allergens associated with intermittent rhinitis, in persistent disease pollens and mites are equally common. ${ }^{3}$ In terms of prevalence rates for PER, there is a marked geographical variation. For example, Bachert and colleagues (2006) reported that in Europe $40 \%$ of cases of allergic rhinitis comprised PER $(35 \%$ had moderate-severe disease) and $60 \%$ intermittent disease (40\% moderate-severe). ${ }^{4}$ However, in Latin America moderate-severe PER accounts for almost $70 \%$ of cases of allergic rhinitis. ${ }^{5}$ This may be explained by the much greater proportion of the year when mite allergen is present, especially in northern regions of the continent (including Central America) with its subtropical climate.

PER is a disease which places a significant burden on patients in terms of nasal allergy symptoms because they affect many aspects of daily life (Fig. 2-2). ${ }^{6}$ Effective treatment to alleviate the symptoms of the disease is important for improving daily functioning and quality of life (QoL). The ARIA guidelines recommend intranasal corticosteroids as first-line therapy in patients with moderate-severe PER. ${ }^{1}$ However, second-generation nonsedating antihistamines remain an important therapeutic option (Fig. 2-3). As noted in the ARIA guidelines pharmacological therapy for PER needs to take into account a number of factors including: efficacy, safety, cost-effectiveness, patient preference, objectives of treatment, likely adherence to treatment recommendations, severity and control of the disease, and the presence of comorbidities. Patient preference is an important and often underrated consideration, since usage statistics show that nonsedating antihistamines are more widely used than intranasal corticosteroids in many counties worldwide, which is contrary to ARIA guideline recommendations. An almost identical situation has been reported in Latin America with twothirds of physicians prescribing antihistamines for their PER patients despite the majority of them having moderate-severe disease. ${ }^{7}$ Interestingly, most physicians $(82 \%)$ prescribed antihistamines short-term (30 days or less) whereas 52\% of physicians prescribed intranasal steroids for less than 30 days.

\section{RUPATADINE: BACKGROUND}

A wide range of nonsedating second-generation of antihistamines are currently available including drugs such as cetirizine, desloratidine, ebastine, fexofenadine, levocetirizine, loratadine, mizolastine, and rupatadine. The one property that they have in common is that they all act at the $\mathrm{H}_{1}$-receptor, and it is therefore likely to be ancillary properties that differentiate the various products and de-

\section{Impact of Nasal Allergy Symptoms on Sufferers \\ Nasal Allergy Symptoms}

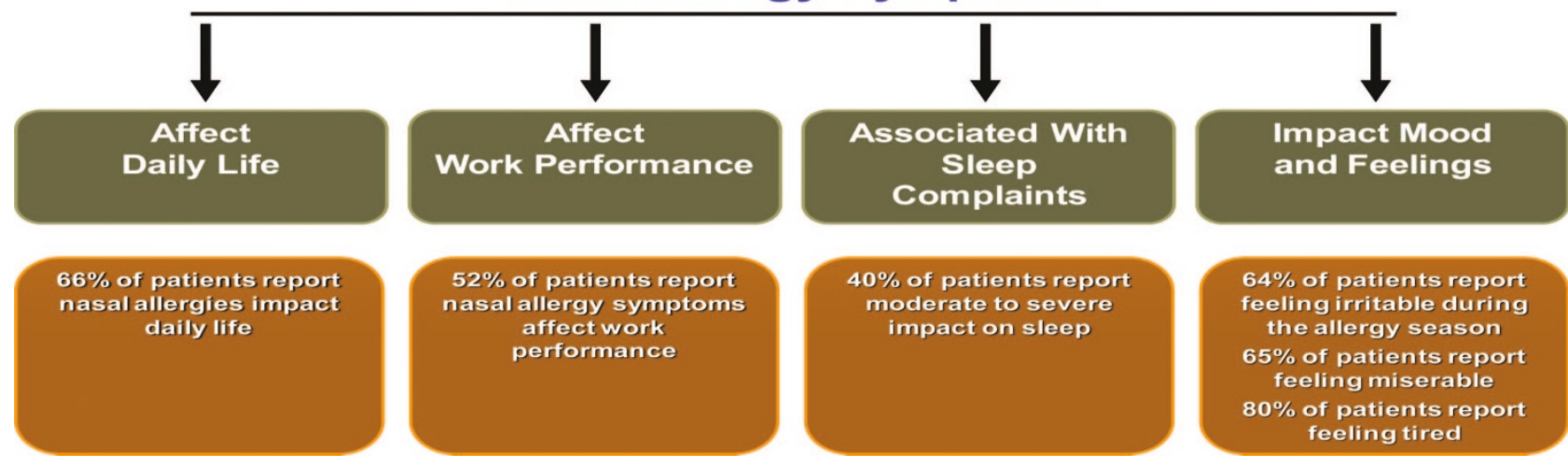

FIGURE 2-2. Impact of nasal allergy symptoms in patients with allergic rhinitis. ${ }^{6}$ 


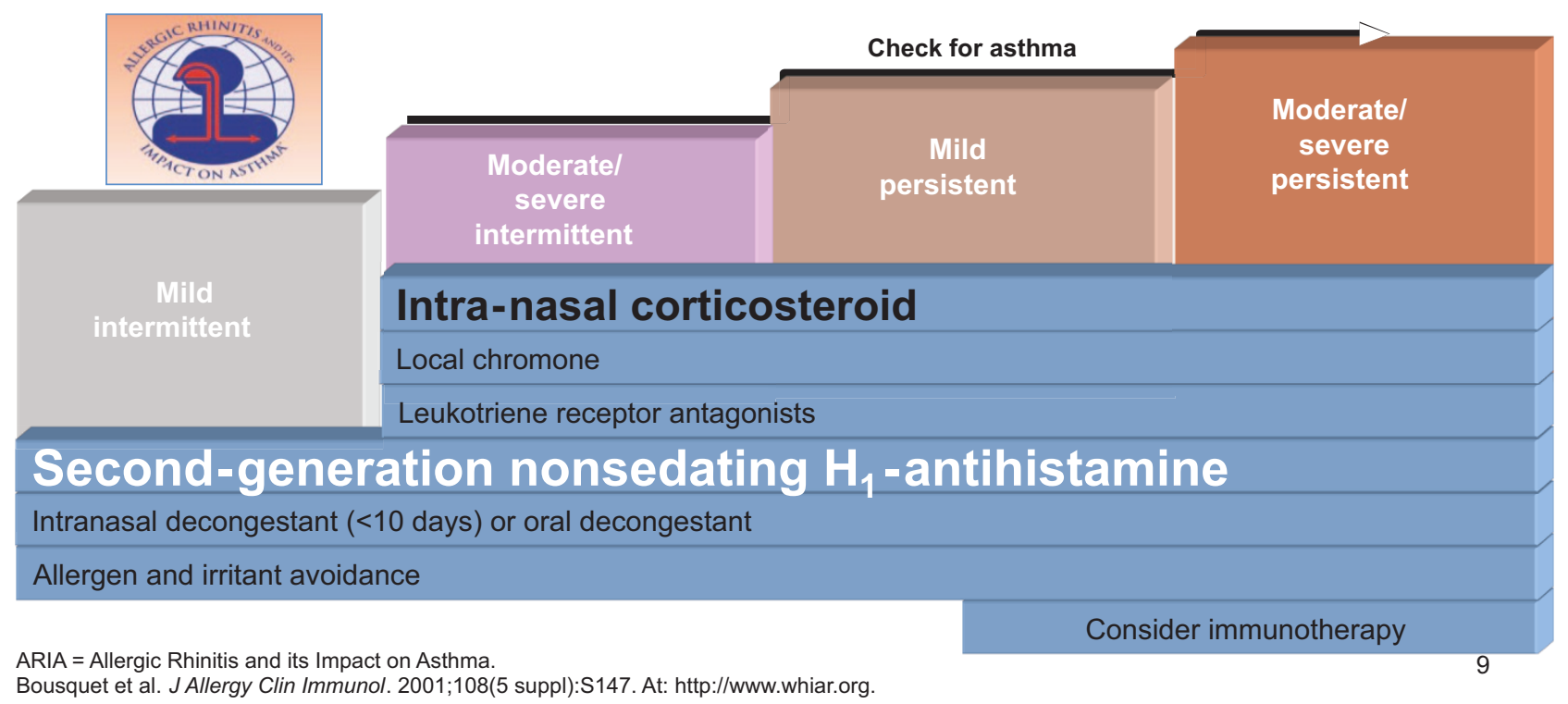

FIGURE 2-3. ARIA treatment guidelines for allergic rhinitis. ${ }^{1,2}$

fines their optimal utility. For example, histamine is clearly not the only mediator involved in the inflammatory process and there is an emerging view that drugs which can inhibit a broader range of inflammatory agents may prove to be more effective in providing symptomatic relief in allergic disorders. ${ }^{8}$ Interestingly, some antihistamines have displayed marginal platelet activating factor (PAF)-antagonistic properties; activity that cannot be attributed to specific interaction with PAF receptors. In contrast, rupatadine appears to be novel in this regard since it specifically inhibits PAF receptor. ${ }^{9-11}$ Furthermore, rupatadine has demonstrated anti-inflammatory effects through inhibition of mast cell degranulation (mediated by various immunologic and nonimmunologic stimuli), and inhibition of eosinophil and neutrophil chemotaxis, cytokine (IL-5, IL-6, IL-8, GM-CSF, and TNF- $\alpha$ ) production, and neutrophil adhesion molecule (CD 11b and CD 18) expression (Fig. 2-4). ${ }^{11}$

\section{RUPATADINE: CLINICAL EVIDENCE}

The efficacy and safety of once-daily rupatadine in the management of allergic rhinitis in adolescents and adults (aged 12-65 years) has been investigated in a broad range of controlled trials (Box 2-1). Results from the dose-ranging trials found the $10 \mathrm{mg}$ once-daily dosage to be optimal in terms of balancing clinical efficacy and safety/tolerability.

\section{Effects in Allergic Inflammation}

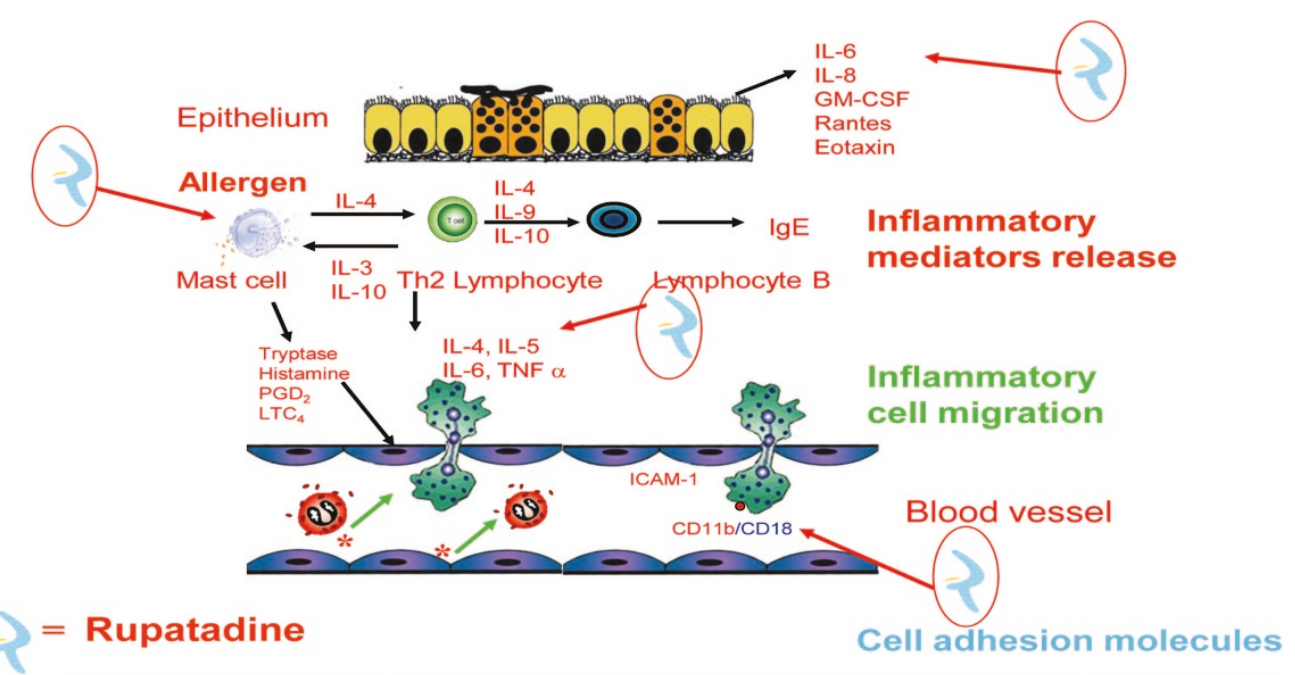

RUPATADINE IMPROVES ALLERGIC INFLAMMATION BY ACTING AT DIFFERENT LEVELS

FIGURE 2-4. Effects of rupatadine in allergic inflammation. 
TABLE 2-1. Change From Baseline in Total Symptom Score at 12 Weeks in ITT Population ${ }^{12}$

\begin{tabular}{|c|c|c|c|c|}
\hline 6TSS & $\begin{array}{l}\text { Placebo } \\
(n=185)\end{array}$ & $\begin{array}{c}\text { Rupatadine } \\
10 \mathrm{mg} \\
(n=183)\end{array}$ & $\begin{array}{c}\text { Cetirizine } \\
10 \mathrm{mg} \\
(n=174)\end{array}$ & Test* \\
\hline \multicolumn{5}{|l|}{ Baseline } \\
\hline Instantaneous & $8.96(3.25)$ & $8.72(2.90)$ & $8.21(3.07)$ & \\
\hline Reflective & $10.15(2.41)$ & $9.90(2.07)$ & $9.69(2.16)$ & \\
\hline \multicolumn{5}{|l|}{ Final } \\
\hline Instantaneous & $5.48(3.65)$ & $4.55(2.90)$ & $4.53(3.40)$ & \\
\hline Reflective & $5.62(3.62)$ & $4.79(2.85)$ & $4.79(3.46)$ & \\
\hline \multicolumn{5}{|l|}{$\begin{array}{l}\text { Change from } \\
\text { baseline }\end{array}$} \\
\hline Instantaneous & $-3.48(3.62)$ & $-4.17(3.23)$ & $-3.67(3.86)$ & $P=0.025$ \\
\hline Reflective & $-4.53(3.44)$ & $-5.11(2.92)$ & $-4.90(3.50)$ & $P=0.067$ \\
\hline \multicolumn{5}{|l|}{$\begin{array}{c}\% \text { Change from } \\
\text { baseline }\end{array}$} \\
\hline Instantaneous & $-38.8 \%$ & $-47.8 \%$ & $-44.7 \%$ & \\
\hline Reflective & $-44.6 \%$ & $-51.6 \%$ & $-50.6 \%$ & \\
\hline
\end{tabular}

- Doses evaluated:

- $2.5,5,10$, or $20 \mathrm{mg}$ rupatadine, once daily

- Treatment duration:

- 14 days (Seasonal Allergic Rhinitis)

- 28 days (Perennial allergic Rhinitis)

- Design:

- International, multicentre, randomized, double-blind

- In parallel groups

- Control group/active treatments:

- Placebo

- Ebastine (10 mg)

- Loratadine (10 mg)

- Cetirizine (10 mg)

BOX 2-1. Clinical trials in allergic rhinitis

\section{Rupatadine in Persistent Allergic Rhinitis (PER)}

In Latin America, a large Phase IV randomized, double-blind, placebo-controlled, 12-week clinical trial was un- dertaken to compare the efficacy and tolerability of rupatadine $10 \mathrm{mg}$ once daily with cetirizine $10 \mathrm{mg}$ once daily in more than 500 patients with confirmed PER according to ARIA criteria. ${ }^{12}$ The main results from the trial, in terms of changes from baseline in total symptom score (TSS) for 6 symptoms after 12 weeks, are shown in Table 2-1, while the changes at 4, 8, and 12 weeks are highlighted in Figures 2-5.

The improvement in TSS was not statistically significant in the placebo group at any time during the study. In contrast, both rupatadine and cetirizine significantly reduced TSS at 4 and 8 weeks compared with baseline values, but only rupatadine produced a statistically significant improvement at 12 weeks $(P=0.008)$.

QoL was also measured in this trial using the Rhinoconjunctivitis Quality of Life Questionnaire (RQLQ) and both rupatadine and cetirizine significantly improved overall scores and scores for the activities, sleep, and nasal symptom domains $(P<0.01)$. However, only rupatadine statistically significantly improved ocular symptoms $(P<0.01$; Fig. 2-6).

Other clinical trials in patients with PER include the XPERT trial ${ }^{13}$ involving levocetirizine and the ACCEPT2 trial ${ }^{14}$ that investigated desloratadine. In both these trials, the antihistamines reduced 5 -symptom TSS by $\sim 40 \%$ and this compares with the 50\% reduction in 6-symptom TSS observed in our Latin American study. Interestingly, it has been shown that long-term antihistamine treatment results in greater reductions in symptoms of PER with time and this was associated with a statistically significant improvement in QoL. ${ }^{13}$

Recently, a 1-year study involving rupatadine $10 \mathrm{mg}$ once daily in patients with PER has been published. ${ }^{15}$ This was an open-label Phase IV safety trial involving 324 patients followed for 6 months and 120 patients who continued treatment for 12 months. Compliance with treatment was very high in this trial; $89.6 \%$ at 6 months and $83.3 \%$ at 12 months. These data indicate a high level of satisfaction, and presumably perceived benefit, by patients taking rupatadine. Overall, the tolerability of rupatadine was very good and the most frequent adverse effects were dry mouth, headache, and somnolence and, interestingly, all 3 adverse effects were decreased at 1-year compared with the incidence at 6 months: 0.83 versus $2.2 \%, 0.83$ versus $6.5 \%$, and 5.8 versus $7.7 \%$, respectively. Another important finding in this trial was the lack of abnormal ECG findings over the 12-month study

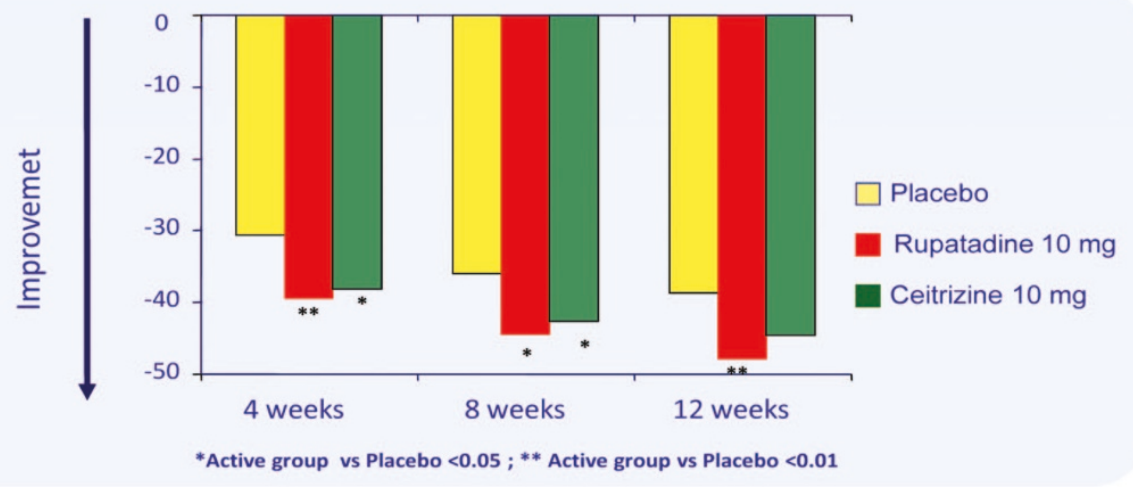

FIGURE 2-5. Change from baseline in instantaneous Total Symptom Score (TSS) at 4, 8, and 12 weeks in patients with persistent allergic rhinitis treated with placebo, cetirizine, or rupatadine. ${ }^{12}$ 


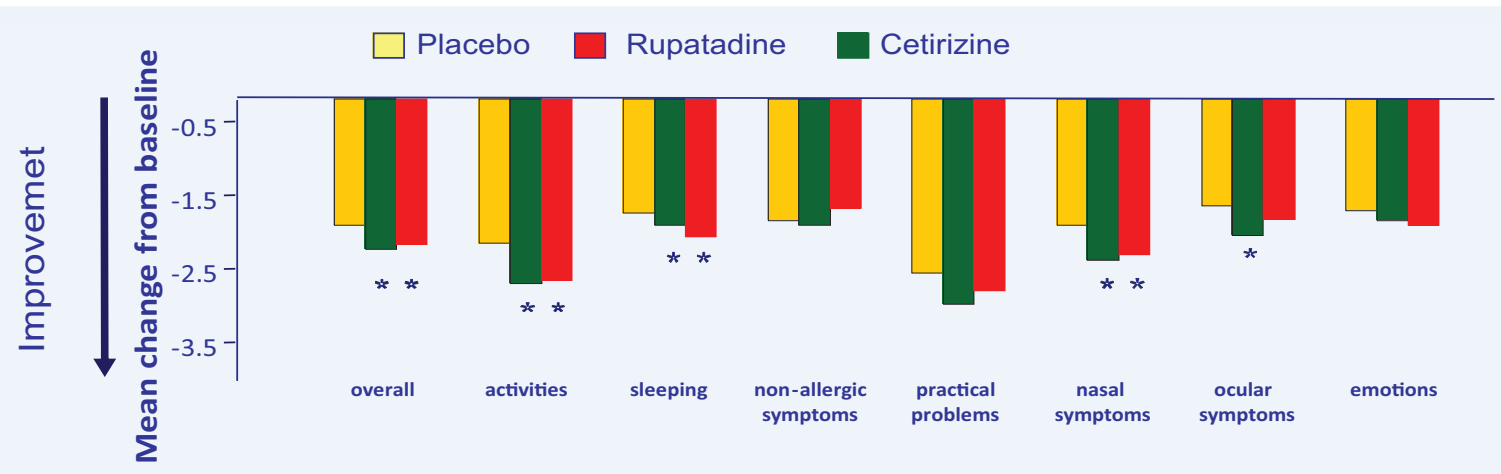

Significant improvements at $p<0.01$ level are marked with *.

FIGURE 2-6. Mean change from baseline in RQLQ domain and overall scores in patients with persistent allergic rhinitis treated with placebo, cetirizine, or rupatadine. ${ }^{12}$

period, suggesting a lack of cardiotoxicity. ${ }^{15}$ QoL was also investigated using the RQLQ questionnaire and rupatadine produced statistically significant improvements in the domains assessing sleep, emotions, and ocular symptoms within 1 month of initiating treatment. ${ }^{16}$ Furthermore, over the 6- and 12-month treatment periods QoL scores continued to improve significantly from baseline values in the rupatadine group $(P<0.0001)$. These findings, combined with those from other clinical trials assessing QoL in patients with allergic rhinitis, have clearly demonstrated the positive benefit that rupatadine has on patient well-being.

\section{Rupatadine; Fast Onset of Action}

From the patient's perspective, rapid relief of nasal symptoms and the return to their usual lifestyle would be an important attribute for any drug used to treat allergic rhinitis. In this regard, rupatadine has been reported to have a fast onset of action in patients with seasonal rhinitis, perennial rhinitis, PER, and chronic urticaria. ${ }^{11}$ In an experimental model using the Vienna Challenge Chamber, rupatadine $10 \mathrm{mg}$ once daily significantly reduced total nasal symptom scores compared with placebo within 15 minutes of allergen exposure. This rapid response compared favorably with results achieved with other antihistamines such as loratadine and levocetirizine that had previously been tested in this model. ${ }^{17}$

\section{CONCLUSIONS}

- In Latin America PER is the most common presentation of allergic rhinitis, representing almost $70 \%$ of cases

- Second-generation antihistamines are a first-line treatment option in patients with moderate-severe disease and seem to be favored over intranasal corticosteroids, despite the latter being the recommended treatment choice in the ARIA guidelines

- Patient preference may play an important role in this treatment choice

- Generally speaking, the antihistamines are used shortterm ( $<30$ days) despite evidence of increased benefits with longer-term treatment
- Rupatadine is a second-generation antihistamine that is also a potent antagonist of PAF-receptors, and it also inhibits other inflammatory mediators/effector cells

- In clinical trials rupatadine was found to be an effective and safe/well-tolerated treatment option in patients with PER; it reduced nasal and ocular symptoms and also improved a number of aspects of the patient's QoL

- With once-daily administration rupatadine had a fast onset of action and an extended duration of activity providing 24-hour cover

- Clinical trials up to 1-year in duration confirmed the safety of rupatadine $10 \mathrm{mg}$ once daily and found no evidence of any cardiotoxic effects

\section{REFERENCES, SECTION 2}

1. Bousquet J, Van Cauwenberge P, Khaltaev N, Aria Workshop Group; World Health Organization. Allergic rhinitis and its impact on asthma. J Allergy Clin Immunol. 2001;108(Suppl 5):S147-S334.

2. Bousquet J, Van Cauwenberge P, Khaled NA, Bachert C, BaenaCagnani CE, Bouchard J, et al. Pharmacologic and anti-IgE treatment of allergic rhinitis (ARIA) update (in collaboration with $\mathrm{GA}^{2} \mathrm{LEN}$ ). $\mathrm{Al}$ lergy. 2006;61:1086-1096.

3. Bousquet J, Annesi-Maesano I, Carat F, Léger D, Rugina M, et al. Characteristics of intermittent and persistent allergic rhinitis: DREAMS study group. Clin Exp Allergy. 2005;35:728-732.

4. Bachert C, van Cauwenberge P, Olbrecht J, van Schoor J. Prevalence, classification and perception of allergic and nonallergic rhinitis in Belgium. Allergy. 2006;61:693-698.

5. Tassinari P. Improvement of symptoms in children 6 to 12 years with allergic rhinitis seen with desloratadine therapy with or without concomitant corticosteroids. J Allergy Clin Immunol. 2007;119(Suppl 1): S63-S64.

6. Shedden A. Impact of nasal congestion on quality of life and work productivity in allergic rhinitis: findings from a large online survey. Treat Respir Med. 2005;4:439-446.

7. Neffen H. Rinitis alérgica en Latinoamérica. Manejo actual y estrategias para la adopción de guías de diagnóstico y tratamiento. Drugs Today. 2009;45(Suppl 4):1-19.

8. Howarth PH, Salagean M, Dokic D. Allergic rhinitis: not purely a histamine-related disease. Allergy. 2000;55:7-16.

9. Merlos M, Giral M, Balsa D, Ferrando R, Queralt M, et al. Rupatadine, a new potent, orally active dual antagonist of histamine and plateletactivating factor (PAF). J Pharmacol Exp Ther. 1997;280:114-121.

10. Merlos M, Balsa D, Giral M, Ferrando R, Garcia-Rafanell J, Forn $\mathrm{J}$. Inhibition of rat peritoneal mast cell exocytosis by rupatadine fuma- 
rate: a study with different secretagogues. Methods Find Exp Clin Pharmacol. 1997;19(Suppl A):148.

11. Mullol J, Bousquet J, Bachert C Canonica WG, Gimenez-Arnau A, et al. Rupatadine in allergic rhinitis and chronic urticaria. Allergy. 2008; 63(Suppl 87):5-28.

12. Fantin S, Maspero J, Bisbal C, Agache I, Donado E, et al. A 12-week placebo-controlled study of rupatadine $10 \mathrm{mg}$ once daily comparative with cetirizine $10 \mathrm{mg}$ once daily, in the treatment of persistent allergic rhinitis. Allergy. 2008;63:924-931.

13. Bachert C, Bousquet J, Canonica GW, Durham SR, Klimek L, et al. Levocetirizine improves quality of life and reduces costs in long-term management of persistent allergic rhinitis. J Allergy Clin Immunol. 2004; $114: 838-844$.

14. Zuberbier T. ACCEPT: a joint study of GA2LEN and Schering Plough on the implementation of the ARIA guidelines. Rev Francaise d'Allergol. 2009;49:S69-S73.

15. Valero A, de la Torre F, Castillo JA, Rivas P, del Cuvillo A, et al. Safety of rupatadine administered over a period of 1 year in the treatment of persistent allergic rhinitis: a multicentre, open-label study in Spain. Drug Saf. 2009;32:33-42.

16. Roger A, Arnáiz E, Valero A, De la Torre F, Castillo JA, et al. Rupatadine $10 \mathrm{mg}$ improves quality of life in long-term treatment of persistent allergic rhinitis [abstract no. 761 plus poster]. $25^{\text {th }}$ EAACI Congress 10-14 June 2006, Vienna.

17. Stuebner P, Horak F, Zieglmayer R, Arnáiz E, Leuratti C, Peréz I, Izquierdo I. Effects of rupatadine vs placebo on allergen-induced symptoms in patients exposed to aeroallergens in the Vienna Challenge Chamber. Ann Allergy Asthma Immunol. 2006;96:37-44.

\section{SECTION 3. EFFECTIVE NEW ANTIHISTAMINES IN DERMATOLOGY: URTICARIA AND OTHER CONDITIONS}

\section{Abstract}

Modern nonsedating antihistamines that target the $\mathrm{H}_{1}$-receptor are the drugs of choice in the treatment of histamine-mediated inflammatory skin disorders such as urticaria. The modern agents, including rupatadine, the latest addition to our repertoire, lack the unwanted effects of older generation antihistamines (sedation and anticholinergic effects) and exhibit additional anti-inflammatory effects. Rupatadine, for example, has been shown to inhibit platelet-activating factor (PAF) and mast cell activation. In well-controlled clinical trials rupatadine has been shown to be safe and effective in treating patients with chronic spontaneous urticaria. For example at a dosage of $20 \mathrm{mg}$ once daily it produced a $>50 \%$ reduction of urticarial activity in 3 of 4 patients treated and more than half the patients achieved a reduction in symptoms exceeding $75 \%$. Importantly, the clinical benefits obtained in these patients were mirrored by improvements in their quality of life. In addition, treatment with rupatadine $20 \mathrm{mg}$ once daily was shown to be effective in treating patients suffering from cold urticaria. Thus, rupatadine, a second-generation antihistamine that is also a potent PAF-antagonist, is a novel and promising new treatment option for patients with urticaria.

\section{INTRODUCTION}

$\mathrm{H}$ istorically, as a class, the $\mathrm{H}_{1}$-antihistamines (AHs) have been commonly used to treat dermatological complaints in which itch is a symptom. This includes disorders such as atopic dermatitis, allergic contact dermatitis, mastocytosis, psoriasis, pruritus, bullous pemphigoid, and urticaria. As a consequence of this, combined with their widespread use in rhinosinusitis, the AHs represent one of the most frequently administered classes of medicine. This has led to concerted effort, which started in the 1930s, to develop more effective and safer/better tolerated products (Fig. 3-1).

The first-generation AHs, however, were beset with significant adverse effects, most notably sedation and impaired psychomotor performance. Since the 1970s, the focus has been directed toward maintaining the potent anti- $\mathrm{H}_{1}$ activity, while improving on the safety profile. This was achieved with the introduction of second-generation AHs and a more recent aim has been to produce agents with no cardiotoxic effects, because 2 of the newer compounds (terfenadine and astemizole) were associated with QTc prolongation and occasional episodes of lifethreatening torsades de pointes. ${ }^{1}$ Interestingly, while safety issues clearly need to be a priority, recent developments have focused on producing AHs that have antiinflammatory effects that are additive to their activity at the $\mathrm{H}_{1}$ receptor. This is based upon the fact that histamine is clearly not the only mediator involved in the inflammatory process, and the current view is that drugs which can inhibit a broader range of inflammatory agents may prove to be more effective in providing symptomatic relief in urticaria. ${ }^{2}$ In this regard rupatadine is an interesting "newer" nonsedating second-generation AH because it has also been shown to be an powerful inhibitor of PAF receptors (for a review see Mullol et al 2008). ${ }^{3}$

In this review the aim is to discuss the benefits of $\mathrm{AH}$ therapy with a focus on rupatadine in the management of urticaria; a common and debilitating disorder in which mast cells play a key pathogenic role.

\section{URTICARIA}

Urticaria is a common debilitating skin disorder that is characterized by wheals, flare/erythema and pruritus, and is often accompanied by angio-edema. Historically, the etiology of the disorder has been poorly defined and this has led to it being referred to as chronic idiopathic urticaria in many instances. However, in recent times many of the underlying causes of urticaria have been better defined and a classification system based upon etiology and other clinical features has been developed (Box 3-1). ${ }^{4}$

\section{Progress in antihistamine development and availability}

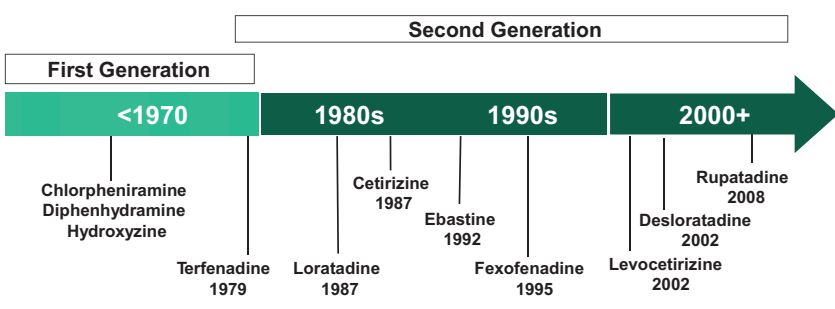

FIGURE 3-1. Development of antihistamines. 


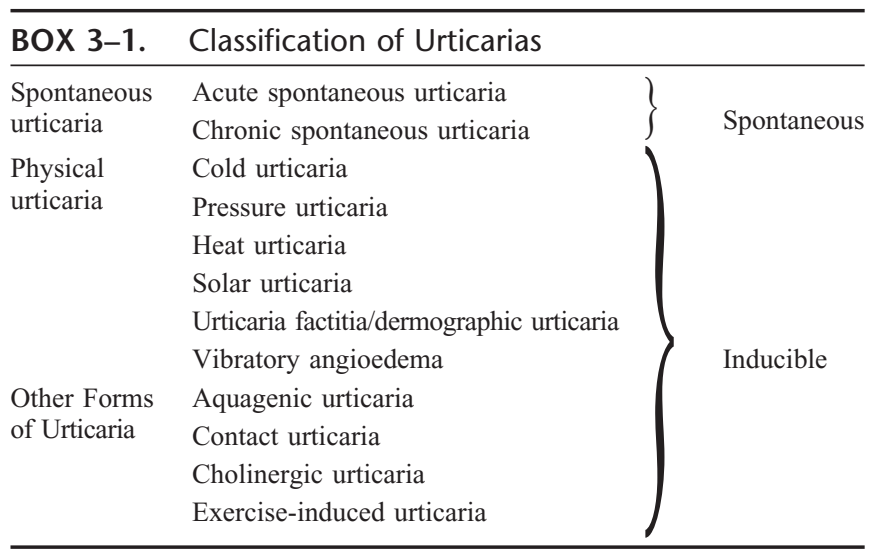

Our current understanding regarding the pathogenesis of urticaria is outlined in Figures 3-2. As can be seen the chain of events leading to the development of urticaria symptoms is initiated by one of the many pathways that result in mast cell activation (Box 1). Activated mast cells respond by releasing a range of mediators of which histamine is the most important, but others such as PAF, various interleukins, GM-CSF, TNF, etc, also contribute to the inflammatory response. Urticarial symptoms are mediated via activation of nerves, vasodilatation of blood vessels in the skin, extravasation of fluid to form a wheal, and recruitment of inflammatory cells.

\section{RUPATADINE IN CHRONIC SPONTANEOUS URTICARIA}

The efficacy of rupatadine has been evaluated in a number of trials involving patients with chronic spontaneous urticaria. In a dose-finding study Dubertret and coworkers (2007) found that rupatadine 10 and $20 \mathrm{mg}$ for 4 weeks significantly reduced mean pruritus severity scores from baseline values by $62 \%(P<0.05)$ and $72 \%(P<0.001)$, respectively, and mean number of wheals by 45 and $58 \%$, respectively. ${ }^{5}$ The investigators' global assessment of symptom severity after 4 weeks was rated as "good improvement" for the majority of patients treated with rupatadine 10/20 mg (Fig. 3-3). Similar improvements in mean pruritus severity scores and mean number of wheals after 4 weeks' treatment with rupatadine 10 and $20 \mathrm{mg}$ was reported by Gimenez-Arnau and colleagues (2007) in patients with chronic spontaneous urticaria. ${ }^{6}$

Importantly, the clinical benefits obtained in this randomized, double-blind, placebo-controlled trials were mirrored by improvements in the quality of life (QoL) of patients (Fig. 3-4).

A pooled analysis of the above 2 studies not only confirmed the efficacy of rupatadine in the treatment of chronic urticaria; a responder analysis highlighted the benefits of using the higher dosage of rupatadine $20 \mathrm{mg}$ once daily (Fig. 3-5). ${ }^{7}$ The authors note that these results support the use of higher than standard dosages of nonsedating antihistamines such as rupatadine for patients with urticaria.

Overall, the results of studies to date confirm that rupatadine 10 and $20 \mathrm{mg}$ are effective and safe in the treatment of chronic spontaneous urticaria. Rupatadine 20 mg was significantly more effective and equally safe compared with rupatadine $10 \mathrm{mg}$. If symptoms persist, we have used rupatadine $40 \mathrm{mg}$ in our clinic with additional clinical benefit.

\section{RUPATADINE IN COLD URTICARIA}

The urticarial response of cold urticaria patients to temperature is extremely variable as can be seen in Figures 3-6. Some individuals react when the temperature is low, whereas others develop wheals at temperatures relatively close to normal skin temperature. ${ }^{8}$

Together with Dr. Gimenez-Arnau and her team at the Hospital del Mar Barcelona, our group undertook a placebo-

\section{Urticaria - Pathogenesis Mast cells are the key effector cells in the induction of urticaria symptoms}

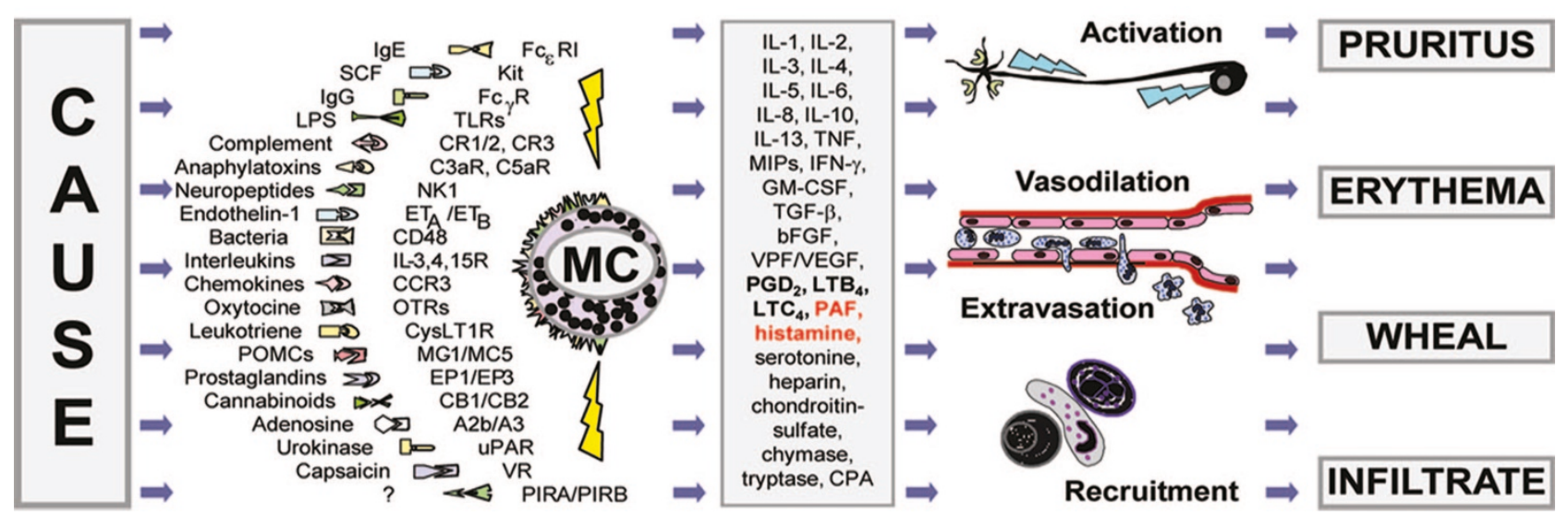

FIGURE 3-2. Pathogenesis of urticaria. 


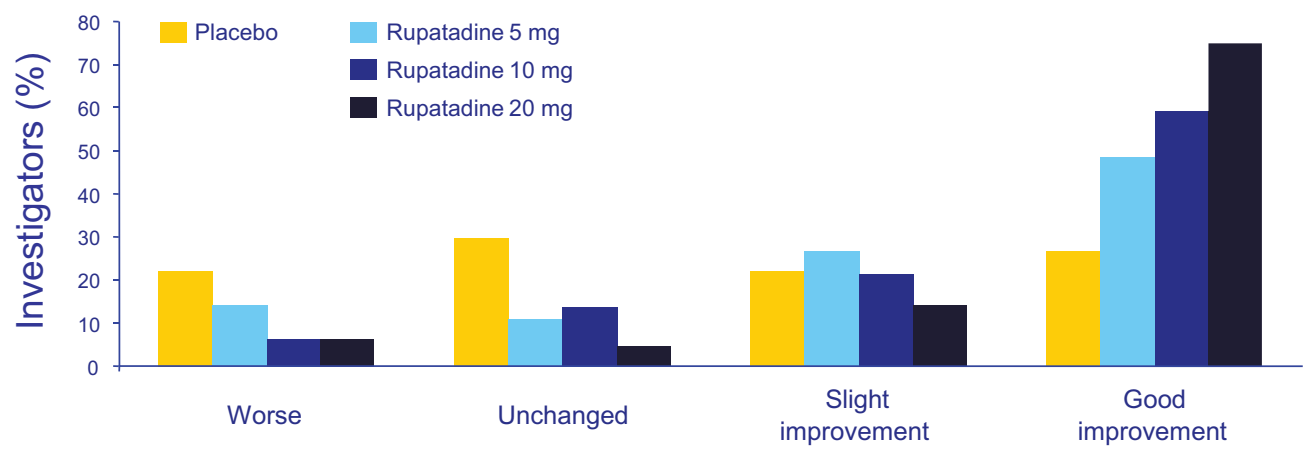

FIGURE 3-3. Investigators' global assessment of symptom severity after 4 weeks treatment with rupatadine 5, 10, and 20 $\mathrm{mg}$ in patients with chronic spontaneous urticaria. ${ }^{5}$

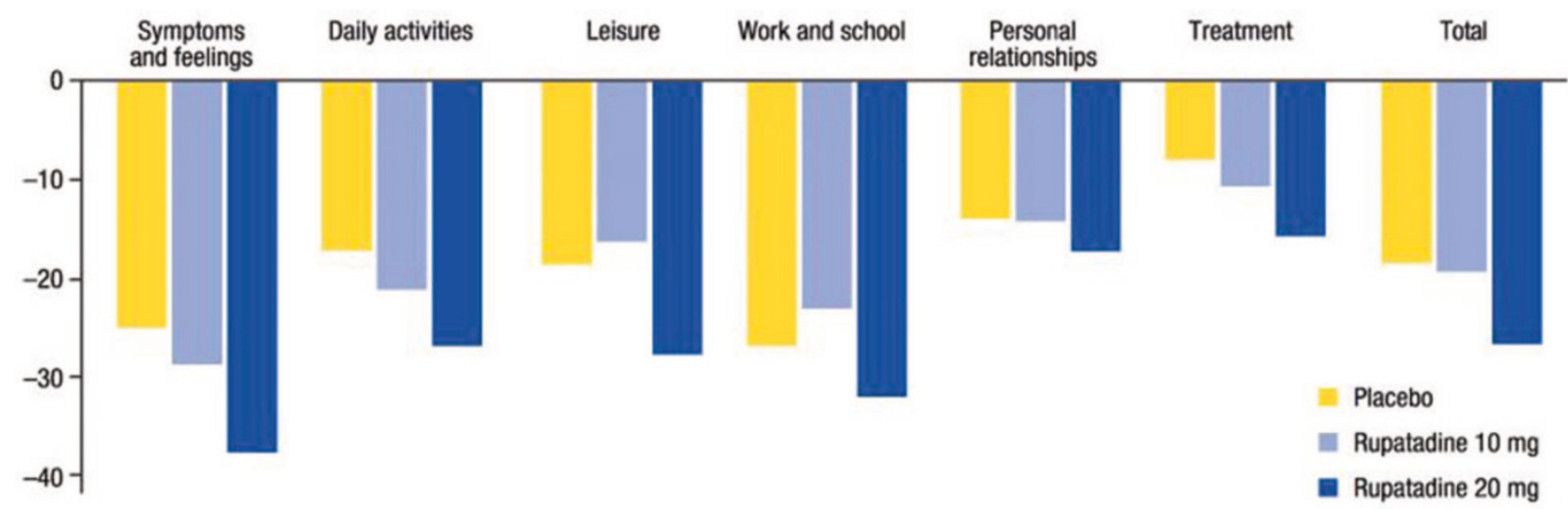

FIGURE 3-4. Improvement in life quality (\%) after 4 weeks' treatment with rupatadine 10 and 20 mg and placebo in patients with chronic spontaneous urticaria. ${ }^{6}$

\section{Meta-analysis \\ Responder rates}

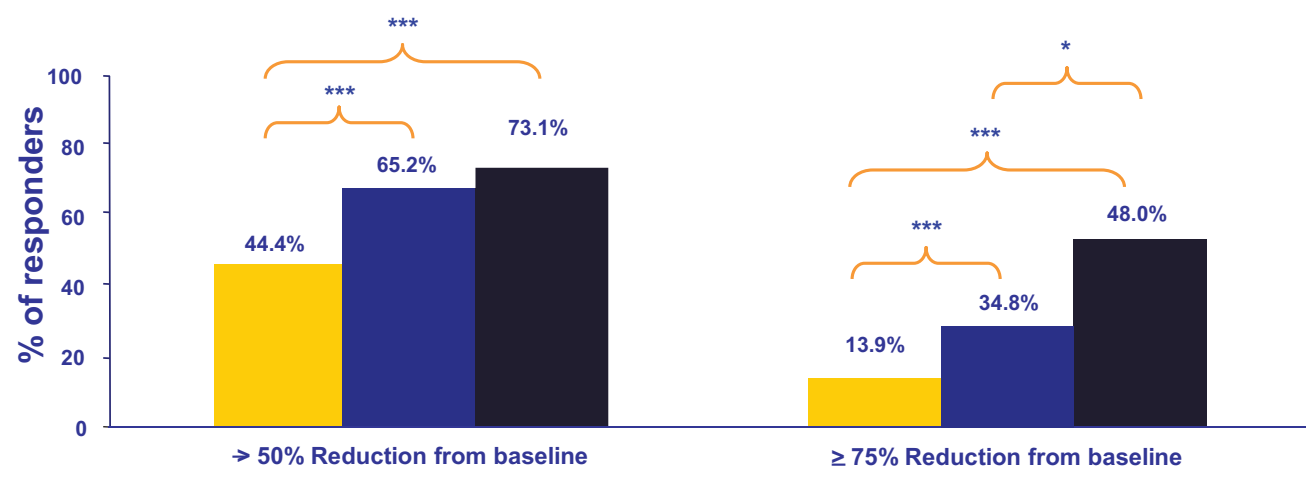

FIGURE 3-5. Responder rates in a pooled analysis of 2 clinical trials involving patients with chronic spontaneous urticaria treated with rupatadine $10 / 20 \mathrm{mg}$ and placebo. ${ }^{7}$

controlled clinical trial to investigate the effects of rupatadine $20 \mathrm{mg}$ on the cold urticaria response in 21 adult cold urticaria patients. ${ }^{9}$ We used TEMP test 3.0, a cold-provocation device that can apply 12 different temperatures to the skin of the patient to determine the critical temperature threshold at which urticaria symptoms occur. In this study rupatadine 20 mg significantly lowered the threshold temperature $(P=$ $0.0006)$ whereas placebo had no effect. Symptoms associated 


\section{Cold urticaria}

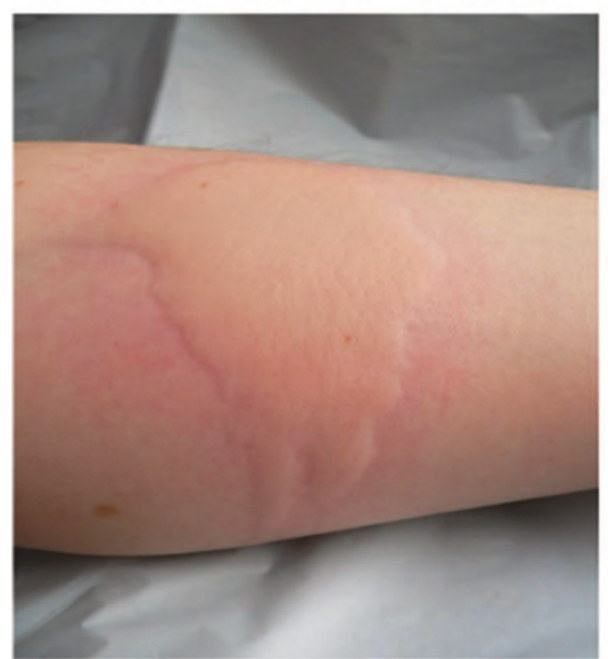

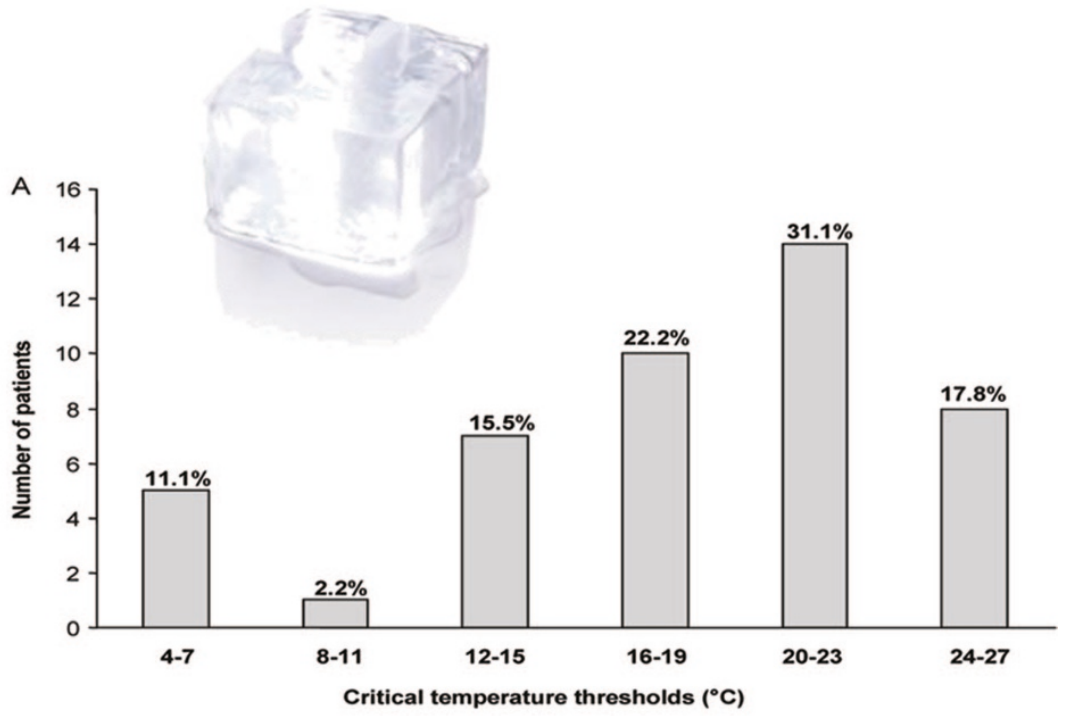

FIGURE 3-6. Critical temperature threshold at which symptoms occur in patients with cold urticaria. ${ }^{8}$

with cold urticaria such as pruritus and burning were also significantly reduced after administration of rupatadine 20 $\mathrm{mg}$, to the point where $>80 \%$ of patients had no or mild reactions after treatment.

\section{ADDITIONAL EFFECTS OF BLOCKING HISTAMINE AND PAF}

Injections of histamine and PAF into the skin both result in a local inflammatory response with a wheal and flare reaction which is associated with itch. ${ }^{10,11}$ These symptoms are identical to those observed after a mosquito bite and have given rise to the view that treatment with rupatadine, which possesses both antihistamine and anti-PAF activity, may help alleviate the reaction to insect bites. This theory was explored in a recent double-blind, placebo-controlled, crossover study in which 30 mosquito bite sensitive adults received either rupatadine $10 \mathrm{mg}$ or placebo once daily for 4 days. ${ }^{11}$ On day 3 during the 2 treatment periods, the participants received 2 bites from an Aedes aegypti mosquito on their forearm. Rupatadine significantly reduced wheal size at 15 minutes by $48 \%$ compared with placebo $(P=0.0003)$ and pruritus by $21 \%(P=0.019)$. For people who react badly to mosquito bites, prophylactic rupatadine once daily may prove to be useful for limiting the wheal/flare/itch response when they visit mosquito endemic areas.

\section{CONCLUSIONS}

- PAF and histamine are important proinflammatory cutaneous mediators

- Urticaria, which is provoked by activated mast cells and their release of proinflammatory mediators such as histamine and PAF, comes in many different forms
- Modern nonsedating antihistamines such as rupatadine are effective in the treatment of chronic spontaneous urticaria

- Rupatadine has also been shown to be effective in other conditions such as cold-induced urticaria and as a protectant against symptoms after mosquito bites.

\section{REFERENCES, SECTION 3}

1. Hove-Madsen L, Llach A, Molina CE, Prat-Vidal C, Farré J, Roura S, Cinca J. The proarrhythmic antihistaminic drug terfenadine increases spontaneous calcium release in human atrial myocytes. Eur J Pharmacol. 2006;553:215-221.

2. Howarth PH, Salagean M, Dokic D. Allergic rhinitis: not purely a histamine-related disease. Allergy. 2000;55:7-16.

3. Mullol J, Bousquet J, Bachert C, Canonica WG, Giménez-Arnau A, et al. Rupatadine in allergic rhinitis and chronic urticaria. Allergy. 2008; 63(Suppl 87):5-28.

4. Zuberbier T, Asero R, Bindslev-Jensen C, Walter Canonica G, Church $\mathrm{MK}$, et al. EAACI/GA2LEN/EDF/WAO guideline: definition, classification and diagnosis of urticaria. Allergy. 2009;64:1417-1426.

5. Dubertret L, Zalupca L, Cristodoulo T, Benea V, Medina I, et al. Once-daily rupatadine improves the symptoms of chronic idiopathic urticaria: a randomised, double-blind, placebo-controlled study. Eur J Dermatol. 2007;17:223-228.

6. Giménez-Arnau A, Pujol RM, Ianosi S, Kaszuba A, Malbran A, et al. Rupatadine in the treatment of chronic idiopathic urticaria: a doubleblind, randomized, placebo-controlled multicenter study. Allergy. 2007; 62:539-546.

7. Gimenéz-Arnau A, Izquierdo I, Maurer M. The use of responder analysis to identify clinically meaningful differences in chronic urticaria patients following placebo-controlled treatment with rupatadine 10 and $20 \mathrm{mg}$. J Eur Acad Dermatol Venereol. 2009;23:1088-1091.

8. Młynek A, Magerl M, Siebenhaar F, Weller K, Vieira dos Santos R, et al. Results and relevance of critical temperature threshold testing in patients with acquired cold urticaria. Br J Dermatol. 2010;162:198-200.

9. Metz M, Scholz E, Ferran M, Izquierdo I, Giménez-Arnau A, Maurer M. Rupatadine improves symptom control and stimulation time and temperature thresholds in Acquired Cold Urticaria. Ann Allergy Asthma Immunol. 2010;104:86-92.

10. Jenks PJ, Kavanagh GM, Brooks J, Bradfield JW, Archer CB. Comparison of weal and flare responses to platelet activating factor (PAF) and 
histamine, and ultrastructural effects of PAF in the skin of atopic and normal subjects. Clin Exp Dermatol. 1999;24:112-117.

11. Thomsen JS, Sonne M, Benfeldt E, Jensen SB, Serup J, Menné T. Experimental itch in sodium lauryl sulphate-inflamed and normal skin in humans: a randomized, double-blind, placebo-controlled study of histamine and other inducers of itch. Br J Dermatol. 2002;146:792-800.

12. Reunala T, Karppinen A, Brummer-Korvenkontio H. Effective treatment of mosquito bites with rupatadine; an experimental study. World Allergy Org J. 2007;(Suppl Nov):S1-S323 (abstract 685).

\section{SECTION 4. MANAGEMENT OF ALLERGIES IN THE PRIMARY CARE ENVIRONMENT}

\section{Abstract}

It is well recognized that globally, allergies of one kind or another, are on the increase. Most countries in the world have a very small number of trained allergists to meet the growing demand for care. In the UK, for example, it has been calculated that there is one specialist allergist per 1.1 million people. Invariably most sufferers visit their general practitioner (GP) in the first instance to determine what the problem is. There is frequently a mismatch in understanding between the GP and patient as to what the diagnosis and solutions are, and this has led some patients to seek alternative practitioners to help fill the "NHS void." Highlighting the nature of the problem are the results from a cross-sectional populationbased survey in Europe that demonstrated that although allergic rhinitis had a relatively high prevalence $(23 \%)$ it frequently went unrecognized (by patients), undiagnosed and untreated or not treated at all. This finding is compounded by results from a GP audit, which reported that a relatively low number of participants with a declared interest in allergic rhinitis and respiratory disorders met the recommendations contained within the Consensus Statement for the management of allergic rhinitis. Possible solutions include the creation of GPs with a special interest (GPSI) in allergy positions in the community, inclusion of structured teaching at the under- and postgraduate level, provision of "how to" literature and greater co-operation between specialists and GPs. Only if we address the situation in a systematic manner will we make an impact on patient care and clinical outcomes.

\section{THE ALLERGY PROBLEM}

G lobally there is a significant increase in the prevalence of allergy, including more serious diseases associated with hospitalization (Fig. 4-1). ${ }^{1}$ In the UK there is a growing professional consensus that both generalist and specialist services are failing to keep up with the increased demand and thus failing to provide acceptable levels of care for many patients with allergy. ${ }^{2}$

A number of theories are proposed to explain this underperformance:

- The relatively high prevalence of allergy. In the UK for example, it has been estimated that $\sim 32 \%$ of the population have suffered from an allergy at some stage (representative values for some other countries are: Japan 40\%, Germany and Sweden 30\%, US and France $20 \%$, and Italy and S. Africa $10 \%)^{3}$

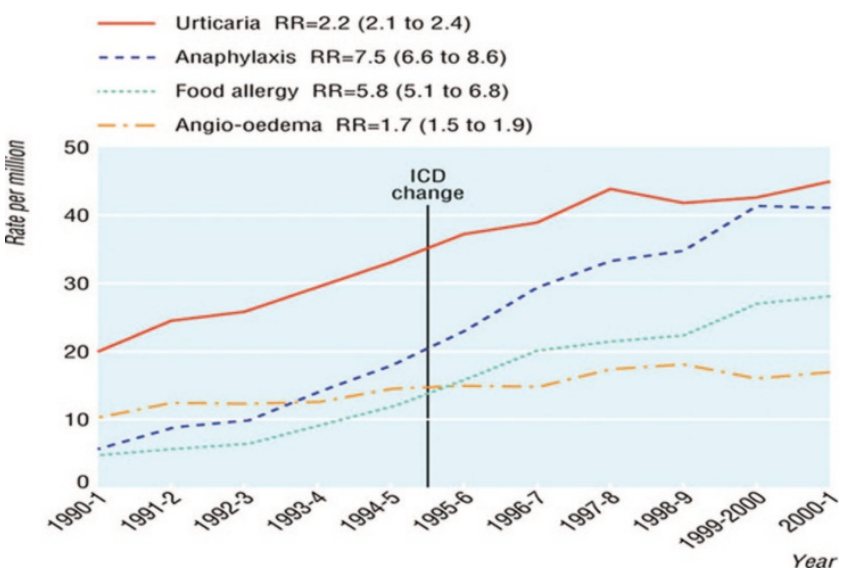

FIGURE 4-1. The changing rate of hospitalizations from certain allergic disorders 1990-2000. ${ }^{1}$

- In the UK there are about 320 million patient/physician consultations per year and about 20 million of these are related to allergic disorders. ${ }^{4,5}$

- And perhaps most enlightening of all is the small number of specialist allergists available to advise and treat allergy patients (for the countries listed above the number are: UK 1:1,083,303; Japan 1:61.200; Germany $1: 16,000$; Sweden 1:42,857; US 1:65.546; France $1: 1,240,000$; Italy $1: 43,200$; S. Africa $1: 1,666,666) .^{3}$

The above numbers highlight the divide between high rates of disease prevalence and low rates of specialist medical care and help to explain the under-recognition, underdiagnosis and undertreatment of allergic rhinitis. In the UK, for example, there are clearly too few allergy specialists for the size of the patient population and certain parts of the country have no cover at all. This gives rise to other issues, and one in particular is the "growth industry" involving providers of so-called alternative treatments and diagnostics (nearly all of them completely unproven) that has developed to fill the "NHS void."

Another potential problem, given the lack of medical resources and time that can be committed to individual patients, is inappropriate and inadequate diagnosis and/or management. Physicians need to understand their patients and listen for warning signals, since we live in an age when allergies are blamed for many complaints, often inappropriately. For example, a patient consulting their physician stating that they believe that they are allergic to peanuts probably is allergic to peanuts. On the other hand a patient who comes to the clinic with a nonspecific complaint such as ...."I have something wrong with me, perhaps it is an allergy".... needs more careful consideration. The term allergy is improperly used by patients and health care professionals alike. When a patient states that they are worried they may have an allergy, it is likely that they are trying to say: I have something wrong with me. I cannot figure out what it is; maybe it's an allergy?

The temptation is to resort to diagnostic tests ( $\mathrm{IgE} /$ skin prick tests) when the more appropriate response is to try and understand the nature of the underlying problem. It may of 
course be an allergy, but it may not. The starting point is to establish what it is that is really concerning the patient. Misinterpretation of diagnostic tests is another potential problem area particularly those results that are obtained from hair or nail samples that have no validity. Results of tests can only be interpreted in the light of the individuals history and symptoms that requires diagnostic skill and judgment. Finally, and perhaps most importantly, we need to consider the patient's expectations from the consultation, which generally are:

- To be taken seriously by their healthcare professional

- To have reasonable investigation of their problem and investigation of possible triggers if it is an allergy

- Advice regarding how to avoid the problem in future

- Appropriate treatment/management

- And to feel that they are being managed appropriately within and integrated healthcare system.

\section{ALLERGIC DISEASES: CURRENT MANAGEMENT SITUATION}

In practice how well are we doing with regards diagnosis of allergic rhinitis? Durham and coworkers (2002) undertook an interesting cross-sectional, population-based, epidemiological survey using computer-assisted telephone interviews to ascertain the prevalence and diagnosis of allergic rhinitis in almost 10,000 adults in 6 European countries. ${ }^{6}$ The main findings of this survey are highlighted in Fig. 4-2 and they demonstrate that allergic rhinitis has a high prevalence in Europe (23\%), it is frequently undiagnosed and often goes untreated. In terms of primary care, our group undertook

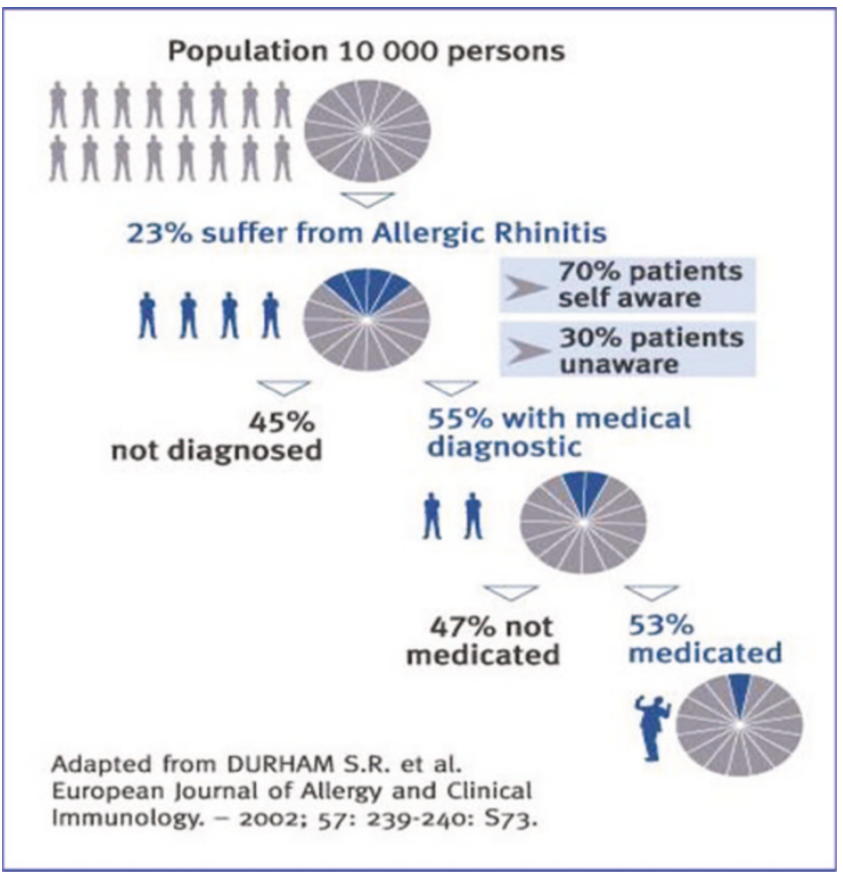

FIGURE 4-2. Results of a cross-sectional population-based, epidemiological survey using computer-assisted telephone interviews to ascertain the prevalence and diagnosis of allergic rhinitis in almost 10,000 adults in 6 European countries. ${ }^{6}$
TABLE 4-1. The Number and Percent of GPs Meeting Consensus Statement Standards for Allergic Rhinitis in a UK Survey $(n=188)$

\begin{tabular}{lcc}
\hline & No. GPs & $\begin{array}{r}\text { Percent of } \\
\text { Total GPs }\end{array}$ \\
\hline $\begin{array}{l}\text { Standard 1: Identification of symptoms } \\
\text { Standard 2: Collection of information to }\end{array}$ & 26 & 13.8 \\
$\quad$ support a clinical diagnosis & 43 & 22.9 \\
$\begin{array}{l}\text { Standard 3: Examining and testing to } \\
\quad \text { support the clinical diagnosis }\end{array}$ & 0 & 0 \\
$\begin{array}{l}\text { Standard 4: Treating and managing the } \\
\quad \text { disease }\end{array}$ & 1 & 0.6 \\
\hline
\end{tabular}

GPS meeting consensus statement standards for allergic rhinitis.

a survey involving approximately 200 general practitioners (GPs) in the UK with a self-declared interest in allergic rhinitis and respiratory disorders, and we compared their management approach with the recommendations contained within the Consensus Statement on the treatment of allergic rhinitis. ${ }^{7}$ The main results from this survey are highlighted in Table 4-1 and demonstrate that relatively few GPs achieved the criteria set out in the Consensus Statement. ${ }^{7}$ It is important to note, however, that the recommendations were designed for secondary care physicians and, so, the findings need to be interpreted in the context of applying specialist standards in a primary care setting. At the time of the survey there were no published guidelines for the management of allergic rhinitis in primary care. This has now been rectified after the publication of guidelines by the International Primary Care Respiratory Group (IPCRG). ${ }^{8}$

The above findings highlight the scope for improvement that can be made in the primary care management of allergic disorders. This is reinforced from results relating to the number of GPs who correctly met the criteria for making an accurate diagnosis and management based upon symptom assessment, elimination of other causes, diagnostic tests, treatment options, etc (Fig. 4-3). ${ }^{7}$ The data are useful because they can assist us in designing future educational programs targeted at areas requiring the greatest improvement.

When the costs of treatment for allergic rhinitis are taken into consideration the above findings become even

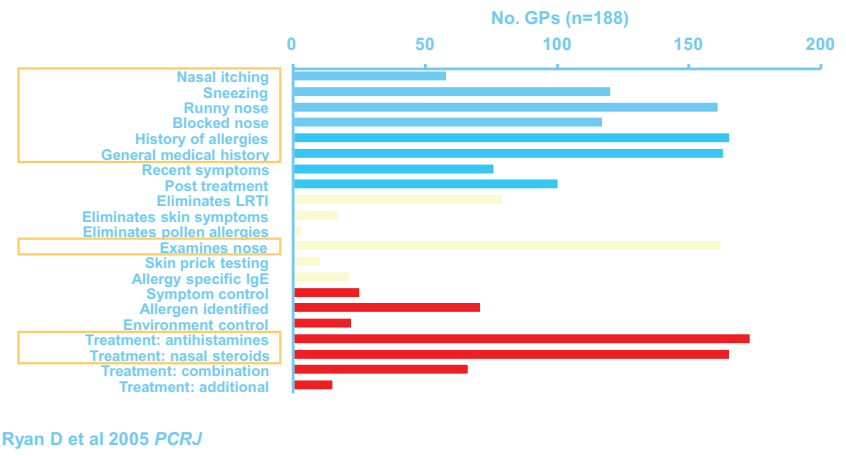

FIGURE 4-3. Number of GPs correctly meeting specific criteria in the Consensus Statement standards for allergic rhinitis in a UK survey $(n=188){ }^{7}$ 
more important. In the UK, for example, the prescription costs for medicines to treat allergic rhinitis are approximately $£ 70$ million and a further $£ 60-70$ million are spent on over-the-counter (OTC) treatments for allergy. Whether these OTC products are the most appropriate for the patient is not known, and there is the possibility that for many patients they are not receiving optimal therapy. For example, many are purchasing first-generation antihistamines that may do more harm than good..$^{9,10}$

\section{ALLERGIC DISEASES: THE FUTURE}

In the UK a working party for the Royal College of Physicians produced a report. "Allergy the unmet need: a blueprint for better patient care" . . that investigated current practices regarding the disease and made recommendations for future progress. ${ }^{2}$ The report looked at disease prevalence trends, the level of disease burden, diagnostic procedures and management, and it also provided recommendations regarding training and delivery of services. The working party made a number of comments relating to the current status of allergic rhinitis:

Royal College of Physicians Report: Allergy the Unmet $\mathrm{Need}^{2}$

- One-third of the population has had a diagnosis of some sort of allergy

- In any year, $20 \%$ of population will receive treatment for an allergic disorder

- Six percent of all GP consultations will be allergy related

and GP-related issues:

Royal College of Physicians Report: GPs and Allergy ${ }^{2}$

- GPs are poorly trained in allergy

- Have little specialist knowledge

- Very little time with patients

- Limited access to skin prick testing,

- Limited access to IgE testing

and they concluded ... "a cycle of lack of knowledge about the most common allergic diseases, lack of recognition of allergic disease at the clinical level, and inadequate knowledge and skills in the diagnosis and treatment of allergic diseases will be perpetuated."

The World Allergy Organization has also recognized the shortcomings of the current situation and they published a report "Recommendations for Competency in Allergy Training for Undergraduates Qualifying as Medical Practitioners: A Position Paper of the World Allergy Organization." 11 In the UK, the Government has tried to address this issue and in 2003/2004 a white paper from the House of Commons Health Committee. . "The Provision of Allergy Services" ... was published and it recognized the need to invest in allergy services and concluded by observing that the current provision of allergy services was manifestly inequitable. ${ }^{12}$ Recommendations included:

- More recognition at undergraduate level

- Better training in allergy for GPs
- Development of GPs with specialist interest (GPSI) in allergy positions

- Minimum of 1 allergy center in each of former NHS regions (5-7 $\mathrm{m}$ population)

- Specialist allergy consultant posts in large teaching hospitals

\section{ROLE OF GPSI IN ALLERGY}

Provision of an efficient allergy service in primary care will require investment as was recognized by the House of Commons Health Committee. ${ }^{12}$ To function effectively it will highly dependent upon having GPSIs in allergy whose role it will be to act as champions and mentors in primary care and to manage more challenging problems in the community; the overall goal will be to improve services, help educate patients and colleagues, and to increase awareness (Box 4-1). ${ }^{13}$

The role will be above and beyond that of providing a simple clinical service. Fig. 4-4 provides an outline of a successful GPSI clinic in allergy that was set-up successfully in London. ${ }^{14}$ For the GPSI in allergy scheme to be successful it will require support:

- From specialist experts in secondary care

- Access to journals/information (especially "how to do articles"; often the costs for information are prohibitive)

- Access to tests

\section{Role of GPs With a Special Interest in Allergy ${ }^{13}$}

1. To manage more challenging problems

- Nasal symptoms unresponsive to combination therapy

- Skin symptoms

- Food allergy and atypical symptoms to food

- Drug reactions

- Generalized insect venom reactions

- Asthma when an allergic trigger is suspected anaphylaxis

2. Advice

- Primary care practitioners

- Primary care organizations and public bodies

3. Access

- Allergy testing (skin prick/IgE testing)

- Imaging

- Allergen injection immunotherapy

- Specialist expertise

4. Education

5. Liaison

- Researchers

- Public health leads

- Clinical governance

BOX 4-1. Role of GPs with a special interest in allergy. ${ }^{13}$ 


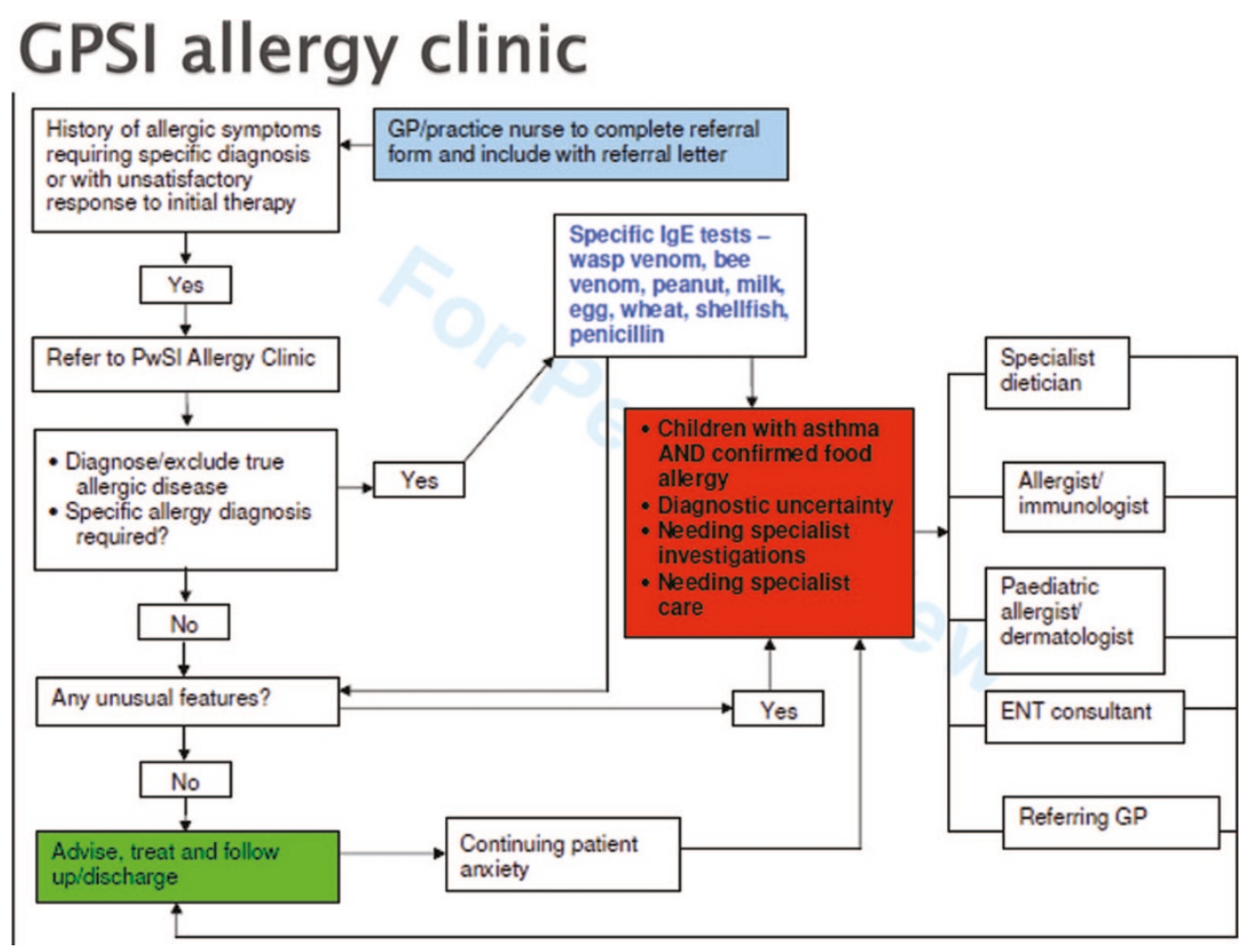

FIGURE 4-4. Outline of allergy services provided by a London clinic managed by General Practitioners with a Special Interest (GPSI) in allergy/respiratory disorders. ${ }^{14}$

\section{CONCLUSIONS}

- Clear evidence that the prevalence of allergic diseases is increasing

- Global shortage of specialist allergists

- Generally there is a poor understanding of allergy management in primary care

- Better education regarding allergy is essential for underand postgraduates

- There is a recognized need that we must deliver care differently to improve patient outcomes

- Campaigning for resources, nationally and internationally is essential

\section{REFERENCES}

1. Gupta R, Sheikh A, Strachan D, Anderson HR. Increasing hospital admissions for systemic allergic disorders in England: analysis of national admissions data. BMJ. 2003;327:1142-1143.

2. Royal College of Physicians. Allergy the unmet need: a blueprint for better patient care. Royal College of Physicians, London; 2003.

3. Warner JO, Kaliner MA, Crisci CD, Del Giacco S, Frew AJ, et al. Allergy practice worldwide: a report by the world allergy organization specialty and training council. Allergy Clin Immunol Int. 2006; 18:4-10.

4. Hippisley-Cox J, Fenty J, Heaps M. Trends in consultation rates in general practice 1995 to 2006: Analysis of the QRESEARCH database. QRESEARCH research highlights. Leeds: The Information Centre, 2007:29. [Available on at http://www.qresearch.org].

5. Hippisley-Cox J, Jumbu G, Fenty J, Holland R, A. P., Heaps M. Primary care epidemiology of allergic disorders: analysis using QRESEARCH database 2001-2006. QRESEARCH research highlights. Leeds: The Information Centre, 2007:84. [Available online at http://www.qresearch.org].

6. Durham SR, Strachan DP, Bauchau V. The prevalence and diagnosis of allergic rhinitis: a cross-sectional population-based epidemiological study in six European countries. Allergy. 2002;57(Suppl 73):239-240.

7. Ryan D, Grant-Casey J, Scadding G, Pereira S, Pinnock H, Sheikh A. Management of allergic rhinitis in UK primary care: baseline audit. Prim Care Resp J. 2005;14:204-209.

8. Price D, Bond C, Bouchard J, Costa R, Keenan J, et al. International Primary Care Respiratory Group (IPCRG) guidelines: management of allergic rhinitis. Prim Care Resp J. 2006;15:58-70.

9. Weiler JM, Bloomfield JR, Woodworth GG, Grant AR, Layton TA, et al. Effects of fexofenadine, diphenhydramine, and alcohol on driving performance. A randomized, placebo-controlled trial in the Iowa driving simulator. Ann Inter Med. 2000;132:354-363.

10. Walker S, Khan-Wasti S, Fletcher M, Cullinan P, Harris J, Sheikh A. Seasonal allergic rhinitis is associated with a detrimental effect on examination performance in United Kingdom teenagers: case control study. J Allergy Clin Immunol. 2007;120:381-387.

11. Potter PC, Warner JO, Pawankar RS, Kaliner MA, Del Giacco A, Rosenwasser L, for the WAO Specialty and Training Council. Recommendations for competency in allergy training for undergraduates qualifying as medical practitioners: a World Allergy Organization Position Paper. World Allergy Org J. 2009;2:150-189.

12. House of Commons Health Committee. The provision of allergy services $6^{\text {th }}$ report of session 2003/2004. House of Commons, London, UK: The Stationary Office Ltd HC 696-1.

13. Ryan D, Levy M, Morris A, Sheikh A, Walker S. Management of allergic problems in primary care: time for a rethink? Prim Care Resp J. 2005; 14:195-203.

14. Levy ML, Walker S, Woods A, Sheikh A. Service evaluation of a UK primary care-based allergy clinic: quality improvement report. Prim Care Resp J. 2009;18:313-319. 